\title{
OBJETIVOS Y ESTRATEGIAS UTILIZADOS PARA CONSOLIDAR A LA FISCALÍA NACIONAL ECONÓMICA COMO UN SERVICIO PÚBLICO CONFIABLE
}

\author{
Felipe Irarrázabal Philippi \\ Universidad Adolfo lbáñez
}

\begin{abstract}
Resumen: En este texto, el ex persecutor económico de la libre competencia da cuenta de los objetivos y las estrategias desarrolladas por la Fiscalía Nacional Económica (FNE) durante su liderazgo, con miras a consolidar un modelo institucional de funcionamiento eficiente, eficaz y consistente, con altas tasas de reputación y confianza. Explica las características principales del derecho de competencia y de la institucionalidad chilena, concentrándose en la independencia técnica y política del organismo persecutor, en la estricta selección de los casos, el tono técnico utilizado, la conformación de equipos de trabajo de alto rendimiento y la internacionalización de la FNE. Finaliza con una reflexión acerca de la confianza en las instituciones, ingrediente clave de un modelo exitoso.
\end{abstract}

Palabras Clave: libre competencia, FNE, TDLC, independencia institucional, confianza institucional.

Clasificación JEL: K21; O17.

Felipe Irarrázabal Philippi. Abogado de la Universidad de Chile. LL.M. por la Universidad de Yale. Visiting scholar Stanford Law School. Ex Fiscal Nacional Económico (2010-2018). Hoy director del Centro de Competencia de la Universidad Adolfo Ibáñez (CeCo). Email: felipe.irarrazabal@uai.cl. 


\title{
THE OBJECTIVES AND STRATEGIES USED TO CONSOLIDATE THE NATIONAL ECONOMIC PROSECUTOR'S OFFICE AS A RELIABLE PUBLIC SERVICE
}

\begin{abstract}
In this text, the former competition prosecutor describes the objectives and strategies developed by the National Economic Prosecutor's Office (FNE) under his leadership with a view to consolidating an institutional model that would function efficiently, effectively and consistently, with high levels of reputation and trust. He explains the main characteristics of Chilean institutions and competition law, concentrating on the technical and political independence of the prosecuting agency, the strict selection of cases, the technical tone used, the formation of high-performing work teams and the internationalization of the FNE. He ends with a reflection on trust in institutions, which is the key to a successful model.
\end{abstract}

Keywords: free competition, FNE, Competition Tribunal, institutional independence, institutional trust.

JEL Classification: K21; O17.

La complejidad del mundo futuro se reduce por medio del acto de confianza. Al confiar, uno se compromete con la acción como si hubiera solo ciertas posibilidades en el futuro. El actor une su futuro en el presente con su presente en el futuro.

Niklas Luhmann, Confianza ${ }^{1}$

\section{INTRODUCCIÓN}

\begin{abstract}
A principios del año 2010, el Presidente Sebastián Piñera me nombró como Fiscal Nacional Económico, a través de un concurso de Alta Dirección Pública, y el año 2014 la Presidente Michelle Bachelet renovó mi nombramiento. Así, tuve el privilegio de liderar la Fiscalía Nacional Económica (en adelante FNE) por algo más de ocho años y de contribuir a que se convirtiera en un servicio público de excelencia.
\end{abstract}

${ }^{1}$ Niklas Luhmann, Confianza, traducción de Darío Rodríguez Mancilla (Barcelona: Anthropos, 2005), 33. 
Quiero partir aclarando que la FNE era un buen servicio público cuando la recibí. ${ }^{2}$ De hecho, la primera medida que adopté recién llegado fue confirmar a todos y cada uno de sus funcionarios en sus cargos. También les aclaré que venía solo. O sea, que nadie externo me acompañaba, ni segundo de a bordo, ni jefe de gabinete, ni secretaria. Esos gestos eran importantes porque se estaba transitando, por primera vez, a partir del retorno de la democracia, desde una coalición de centroizquierda a otra de centroderecha y los funcionarios tenían legítimas dudas sobre su continuidad. ${ }^{3}$

Durante aquellos ocho años lideré la FNE, ésta logró hacer contribuciones importantes a la defensa y promoción de la libre competencia y - creemos - pasó a consolidarse como un servicio público confiable y de excelencia, tanto en Chile como en el extranjero, sin aumentar exponencialmente ni el número de sus funcionarios ni su presupuesto. $^{4}$

2 Es interesante leer el "Balance cuatrienio 2006-2010", de marzo de 2010, en donde el entonces fiscal Enrique Vergara hace un recuento de su gestión, y exterioriza sus anhelos institucionales, los que guardan armonía con lo que se hizo posteriormente: “(...) ser una institución eficiente, que sus acciones estén orientadas y planificadas según su impacto sobre la competencia en los mercados, ser una institución reconocida en el país, a nivel técnico y ciudadano, ser una institución validada ante sus pares extranjeros". Allí también da cuenta de sus principales desafíos: "incorporación de las nuevas facultades que en materia de colusión y carteles establece la Ley 20.361" e "incrementar la efectividad de los requerimientos presentados por la FNE, particularmente en casos de colusión”. Disponible en http:// www.fne.gob.cl/wp-content/uploads/2010/12/inan_0005_2010.pdf.

${ }^{3}$ Además, y para reforzar la señal de continuidad, colgamos los retratos de todos los fiscales anteriores en la sala principal de reuniones de la FNE, algo que es bastante usual en los servicios públicos chilenos, pero que no se estilaba en la FNE. Asimismo, invitamos a los ex fiscales (incluyendo a doña Olga Feliú, señora de Waldo Ortúzar) a una reunión donde les planteamos el proyecto de un libro sobre la libre competencia en Chile que requería las entrevistas de cada uno de ellos, a lo cual accedieron de inmediato. Patricio Bernedo, profesor de historia de la Pontificia Universidad Católica de Santiago, escribió el libro, luego de entrevistarlos. Patricio Bernedo, Historia de la libre competencia en Chile (1959-2010) (Santiago: Fiscalía Nacional Económica, 2013), disponible en http:/www.fne.gob.cl/wpcontent/ uploads/2013/11/Historia_libre_competencia.pdf.

${ }^{4}$ El número total de funcionarios aumentó entre los años 2010 y 2018 de 87 a 115, y el presupuesto, de 3.940 a 6.981 millones de pesos (en pesos nominales de las respectivas leyes de presupuestos). 
En estos años fuimos capaces de perfeccionar un modelo de funcionamiento de la FNE que respetara los tiempos, objetivos y sello de la institución, consolidamos su reputación y se produjeron resultados concretos que fueron percibidos por la ciudadanía, por los actores políticos del país y por el mundo empresarial. ${ }^{5}$

Ese modelo se basaba en los siguientes pilares, como se lee en nuestra cuenta pública del 2017:

El modelo de la FNE es complejo y se apoya - creo- en al menos nueve pilares básicos. Esos pilares son la autonomía, que hay que defender a sangre y a fuego, contra viento y marea; el carácter técnico, alejado de juegos políticos de salón; el enfoque selectivo, tanto en casos como en profesionales que se integran a nuestro equipo; la constante evaluación de nuestro desempeño, aunque duela; nuestra exigencia de contar con una visión estratégica de largo plazo y actuar en sintonía con dicha visión; ser transparentes en lo que la ley nos lo permite; la humildad para recurrir a asesorías externas especializadas; la necesidad de mantener una integración internacional, en especial con los centros principales de creación de reglas de competencia, y mantener una clara estrategia con los medios de comunicación. ${ }^{6}$

¿Cómo lo hicimos? Eso es lo que quiero relatar en este artículo: los objetivos esenciales que nos guiaron y las estrategias específicas utilizadas para concretar tales objetivos, estrategias que nos permitieron en estos ocho años consolidar un modelo institucional de funcionamiento eficiente, eficaz y consistente, que se tradujo en una mejora en la reputación y en la confianza hacia el derecho de competencia.

${ }^{5}$ Ver Virginia Rivas, "La reputación técnica y el emprendimiento de políticas como fuente de poderes: el caso de la Fiscalía Nacional Económica”, Estudios Públicos 152 (2018). Disponible en https://www.cepchile.cl/cep/site/artic/20181226/ asocfile/20181226123254/rev152_rivas.pdf, en especial sobre la relación entre independencia y reputación. Ver también Francisco Agüero y Santiago Montt, "Chile: The Competition Law System and the Country's Norms", en The Design of Competition Law Institutions: Global Norms, Local Choices, editado por E. Fox \& M. Trebilcock (Oxford: Oxford University Press, 2013).

${ }^{6}$ Ver Cuenta Pública del año 2017 del Fiscal Nacional Económico, en http:// www.fne.gob.cl/wp-content/uploads/2018/04/Discurso_final.pdf. 
Necesitamos, eso sí, antes de desarrollar esos objetivos y estrategias, explicar las características principales del derecho de competencia y de la institucionalidad de nuestro país. ${ }^{7}$

Este trabajo se organiza, en lo que sigue, bajo los siguientes capítulos: (2) complejidad y simpleza del derecho de competencia, (3) consolidación institucional, (4) independencia, (5) selección, (6) tono técnico, (7) equipos de trabajo, (8) internacionalización, (9) confianza y (10) reflexión final.

\section{COMPLEJIDAD Y SIMPLEZA DEL DERECHO DE COMPETENCIA}

El derecho de la competencia, esto es, la regulación que protege a la economía de mercado, es complejo. Enmarañado e impredecible, dirán algunos. En contraste, las leyes que regulan estas materias tienden a ser sencillas y austeras. Insípidas, dirán otros.

La complejidad arranca de lo protegido. La economía de mercado es una forma de organización de por sí compleja y novel, con expresiones prácticas que difieren de lo que podemos aprender de textos teóricos de economía.

El trabajo de los organismos de libre competencia consiste en trazar una línea entre la crueldad propia de la economía de mercado y el reproche anticompetitivo, en un paisaje que presenta grises, echando mano a una ciencia económica que es dinámica y desprecia todo formalismo, con el fin de construir un edificio jurídico sólido pero flexible, que soporte el paso del tiempo y que irradie sentido común.

Eso no es fácil.

Quizás esto se entienda mejor si recurrimos a una analogía: la economía de mercado no debiera ser un cuadrilátero de ring donde todo está permitido, pero tampoco una práctica de tai chi.

La economía de mercado se basa en la competencia, y la competencia ofrece un juego vibrante, que destila una tensión y fuerza entre los equipos rivales en beneficio de los consumidores. Hay ahí un aire

${ }^{7}$ Las personas entendidas en el derecho de la competencia pueden saltarse los primeros dos capítulos (sobre "Complejidad y simpleza del derecho de competencia" y sobre "Consolidación institucional") y partir revisando el capítulo de la independencia. 
de destrucción creativa y un espíritu de incertidumbre en el ambiente, donde nadie tiene asegurado el futuro.

La dificultad viene cuando se tienen que investigar casos concretos o dar orientaciones específicas. La mayoría de las veces es posible distinguir cuándo una conducta empresarial es inapropiada y no está basada en la competencia, en el mérito y en la eficiencia, sino en el abuso o la conspiración. Pero a veces no es sencillo saber, a buenas y primeras, si una conducta es legal o no.

El conocimiento a fondo de los hechos y del mercado en que ellos se desenvuelven es esencial. Pero eso es caro y lento, y, una vez que se tiene, recién empieza la búsqueda de reglas y estándares.

El entramado legal del derecho de la competencia incluye instancias, procedimientos y estándares que tienen particularidades respecto de las tradiciones (en especial sobre las fuentes del derecho), en donde la teoría económica se combina con, por ejemplo, elementos de derecho económico, derecho administrativo, derecho penal, derecho constitucional y métodos de argumentación de raigambre anglosajona.

La fuente principal normativa es la jurisprudencia de las instancias decisorias y las guías y doctrinas dictadas por las autoridades administrativas. Se requiere un esfuerzo mental doble: de inducción (sobre el estándar que destila un caso concreto ya resuelto) y deducción (sobre la aplicación de ese estándar a un nuevo caso concreto).

Debido a que la institucionalidad de cada país tiene recursos limitados, y cada caso consume mucha energía, se tramita año a año generalmente un número limitado de ellos. Esos pocos casos demoran tiempo en decidirse, dependiendo del régimen de recursos judiciales existentes.

La resolución o sentencia precisa los hechos sobre los que se desenvuelve el caso y luego concluye si ha habido o no una infracción, pasando por referencias a las leyes, precedentes y principios aplicables.

Sin embargo, a veces no queda claro el razonamiento que se aplicó o no se pueden destilar reglas o estándares precisos de éste. Esa timidez o falta de articulación hace difícil pronosticar cómo se resolverá un caso parecido a futuro, desvaneciéndose la posibilidad de que esa sentencia genere una externalidad positiva en el derecho de la competencia.

Otro desafío es que el grupo de personas que está más capacitado para entender las claves de los casos y sus resoluciones o sentencias es 
reducido, y por ello el efecto pedagógico de una resolución o sentencia puede verse disminuido.

Algunos de los desafíos arriba anotados se pueden agudizar en los países de tradición jurídica continental, en la que los jueces fallan generalmente caso a caso y la jurisprudencia no es considerada una fuente vinculante de primer orden. En los países de cultura jurídica anglosajona, en cambio, los jueces de la máxima jerarquía pueden excepcionalmente alejarse del precedente, pero deben argumentar en profundidad por qué se están apartando de lo fallado en casos anteriores y por qué la nueva regla o estándar es superior al anterior. ${ }^{8}$

En esta área del derecho, la jurisprudencia y la doctrina extranjera ejercen un influjo de relevancia. En general, reina bastante la convergencia. Sin embargo, puede ocurrir que esa influencia no sea pacífica y existan puntos de vista contradictorios entre las distintas autoridades extranjeras respecto a un mismo tema, amén de las dificultades propias de todo trasplante. ${ }^{9}$

Otro desafío se refiere a la cuantificación de las consecuencias económicas de una determinada conducta abusiva u operación de concentración. El mundo de los efectos es de por sí vaporoso y supone apuntarle a qué podría ocurrir en el futuro y construir contrafactuales, algo de lo cual no es fácil presumir.

La principal sanción de una infracción de libre competencia es la multa. La determinación del monto de la multa conlleva cierta complejidad, porque hay varios factores que hay que sopesar, algunos de los cuales se mencionan explícitamente en la ley. Pueden también

\footnotetext{
${ }^{8}$ Una expresión anecdótica de la fuerza de los precedentes la encontramos en el caso State Oil Co. v. Khan, 522 U.S. 3 (1997) resuelto por el juez estadounidense Richard Posner, quien falló siguiendo los precedentes, pero advirtiendo que ello era del todo inadecuado, lo que fue revertido posteriormente por la Corte Suprema. Ver Daniel Crane, Antitrust (Nueva York: Wolters Kluwer Law, 2014), 82.

${ }^{9}$ Por cierto, hay que ser muy cuidadosos con la tentación del copy-paste, máxime cuando la importación es parcial (y no comprende una serie de consideraciones institucionales del país donde se aplica) o el argumento se arma con características de distintas jurisdicciones (en lo que podría denominarse un Frankenstein legal). Sobre las distintas visiones imperantes en Estados Unidos y Europa, ver Daniel J. Gifford y Robert T. Kudrle, The Atlantic Divide in Antitrust: An Examination of US and EU Competition Policy (Londres y Chicago: University of Chicago Press, 2015).
} 
imponerse otras sanciones $u$ ofrecerse medidas en una operación de concentración, tales como la prohibición de hacer algo determinado, cuyos efectos pueden reconfigurar una industria entera, o incluso varios mercados. ${ }^{10}$

Como una constatación de esta complejidad, el laureado premio Nobel de Economía Ronald Coase decía sentirse cansado del derecho de la competencia porque cuando los precios subían los jueces decían que eran explotativos; cuando bajaban, que había predación, y cuando se mantenían iguales, que estaba ocurriendo una colusión tácita. ${ }^{11}$

En un sentido similar, aunque con mayor acidez, el juez estadounidense de la Corte Suprema Oliver Wendell Holmes se quejaba de que la Sherman Act era "un engaño basado en ignorancia económica e incompetencia", aunque fuera él mismo quien en su aplicación hizo aportes jurisprudenciales esenciales que permitieron el correcto funcionamiento del derecho de la competencia. ${ }^{12}$

En suma, la complejidad del derecho de la competencia se refleja en que lo protegido es en sí complejo; no hay en general reglas precisas sino estándares que se desprenden de fallos que pueden ser difíciles de entender; confluyen distintas ramas del derecho; prima un análisis consecuencialista más que formalista, y suele tener importancia el derecho comparado.

Como habíamos adelantado, las leyes de competencia son simples, en contraste con la complejidad recién descrita, y así ocurre en los lugares de creación y liderazgo del derecho de la competencia.

${ }^{10}$ Conscientes de lo delicado de adoptar decisiones en materia de libre competencia por sus consecuencias y por la posibilidad de que esa decisión sea errada, la academia ha tomado prestado de la estadística los conceptos de "falso negativo" o "error tipo II" (exonerar o dejar libre a alguien que infringió la norma) y "falso positivo" o error tipo I (castigar a un inocente). Así, se reconoce que una decisión o un fallo pueden estar errados, y se analizan los posibles efectos de tales errores, comparando ambas situaciones, la de exculpación y la de liberación.

${ }^{11}$ William Landes, "The Fire of Truth: A Remembrance of Law and Econ at Chicago", Journal of Law and Economics 26 (1983).

${ }^{12}$ Carta del juez de la Corte Suprema de Estados Unidos Oliver Wendell Holmes a Sir Frederick Pollock, fechada el 23 de abril de 1910. Sobre la importancia del juez en libre competencia, ver Spencer Weber Waller, "The Modern Antitrust Relevance of Oliver Wendell Holmes”, Brooklyn Law Review 59 (1994), 1443. 
En efecto, tanto la ley inicial de Estados Unidos, la Sherman Act, ${ }^{13}$ como el tratado europeo ${ }^{14}$ son sencillos en la descripción del ilícito, al igual que nuestra legislación.

${ }^{13}$ Estados Unidos tiene dos artículos esenciales, ambos contenidos en la Sherman Act de 1890, sobre el ilícito anticompetitivo. La primera sección prohíbe los carteles, en los siguientes términos: "Every contract, combination in the form of trust or otherwise, or conspiracy, in restraint of trade or commerce among the several States, or with foreign nations, is declared to be illegal. Every person who shall make any contract or engage in any combination or conspiracy hereby declared to be illegal shall be deemed guilty of a felony, and, on conviction thereof, shall be punished (...)". Por su parte, la segunda sección se refiere a la monopolización en los siguientes términos: "Every person who shall monopolize, or attempt to monopolize, or combine or conspire with any other person or persons, to monopolize any part of the trade or commerce among the several States, or with foreign nations, shall be deemed guilty of a felony (...)". Hay otras leyes que también establecen prohibiciones en el derecho de la competencia, tales como Clayton Act (1914), $\mathrm{Fe}$ deral Trade Commission Act (1914), Robinson-Patman Act (1936), Celler-Kefauver Act (1950) y Hart-Scott-Rodino Act (1976). Ver Einer R. Elhauge y Damien Geradin, Global Antitrust Law and Economics (Foundation Press, 2018), 11.

${ }^{14}$ La Unión Europea regula el ilícito anticompetitivo también en dos normas esenciales. En relación con los carteles, el artículo 101 del tratado establece: "The following shall be prohibited as incompatible with the internal market: all agreements between undertakings, decisions by associations of undertakings and concerted practices which may affect trade between Member States and which have as their object or effect the prevention, restriction or distortion of competition within the internal market, and in particular those which: (a) directly or indirectly fix purchase or selling prices or any other trading conditions; (b) limit or control production, markets, technical development, or investment; (c) share markets or sources of supply; (d) apply dissimilar conditions to equivalent transactions with other trading parties, thereby placing them at a competitive disadvantage; (e) make the conclusion of contracts subject to acceptance by the other parties of supplementary obligations which, by their nature or according to commercial usage, have no connection with the subject of such contracts". Respecto a los abusos de posición dominante, el artículo 102 determina: "Any abuse by one or more undertakings of a dominant position within the internal market or in a substantial part of it shall be prohibited as incompatible with the internal market in so far as it may affect trade between Member States. Such abuse may, in particular, consist in: (a) directly or indirectly imposing unfair purchase or selling prices or other unfair trading conditions; (b) limiting production, markets or technical development to the prejudice of consumers; (c) applying dissimilar conditions to equivalent transactions with other trading parties, thereby placing them at a competitive disadvantage; (d) making the conclusion of contracts subject to acceptance by the other parties of supplementary obligations which, by their nature or according to commercial usage, have no connection with the subject of such contracts". Hay además regulaciones y directivas, como fuentes secundarias del derecho de competencia. Ver Elhauge y Geradin, Global Antitrust Law..., 52. 
En el caso de la ley chilena, el corazón del derecho de la competencia se encuentra en dos palabras: "libre competencia", ${ }^{15}$ cuyos orígenes se remontan a la Ley 13.305, de 1959, aprobada durante el gobierno del Presidente Jorge Alessandri. ${ }^{16}$

La ley chilena, siguiendo la tradición comparada, no define qué se entiende por "libre competencia", el bien jurídico protegido. ${ }^{17}$

${ }^{15}$ El ilícito del derecho de la competencia de nuestro país se encuentra en el artículo 3 del Decreto Ley 211, de 1973, que "fija normas para la defensa de la libre competencia", el cual ha sufrido varias modificaciones desde su origen en el año 1959. La ley de 1959 establecía: "Todo acto o convención que tienda a impedir la libre competencia dentro del país, sea mediante convenios de fijación de precios o repartos de cuotas de producción, transporte o de distribución, o de zonas de mercado; sea mediante acuerdos, negociaciones o asociaciones para obtener reducciones o paralizaciones de producción; sea mediante la distribución exclusiva, hecha por una sola persona o sociedad, de varios productores del mismo artículo específico, o por medio de cualquier otro arbitrio que tenga por finalidad eliminar la libre competencia, será penado con presidio menor en cualquiera de sus grados y con multa de uno por ciento al diez por ciento del capital en giro de los autores". El actual texto legal vigente dispone: "El que ejecute o celebre, individual o colectivamente cualquier hecho, acto o convención que impida, restrinja o entorpezca la libre competencia, o que tienda a producir dichos efectos, será sancionado (...). Se considerarán, entre otros, como hechos, actos o convenciones que impiden, restringen o entorpecen la libre competencia o que tienden a producir dichos efectos, los siguientes: a) Los acuerdos o prácticas concertadas que involucren a competidores entre sí, y que consistan en fijar precios de venta o de compra, limitar la producción, asignarse zonas o cuotas de mercado o afectar el resultado de procesos de licitación, así como los acuerdos o prácticas concertadas que, confiriéndoles poder de mercado a los competidores, consistan en determinar condiciones de comercialización o excluir a actuales o potenciales competidores. b) La explotación abusiva por parte de un agente económico, o un conjunto de ellos, de una posición dominante en el mercado, fijando precios de compra o de venta, imponiendo a una venta la de otro producto, asignando zonas o cuotas de mercado o imponiendo a otros abusos semejantes. c) Las prácticas predatorias, o de competencia desleal, realizadas con el objeto de alcanzar, mantener o incrementar una posición dominante". Las cursivas son nuestras. El origen de las palabras "libre competencia" se encuentra en un proyecto de ley de 1957 de Carlos Ibáñez del Campo que no fue aprobado y en la asesoría de los economistas estadounidenses que formaron parte de la misión Klein-Saks.

${ }^{16}$ Ver Acta del Congreso Nacional, de fecha 18 de marzo de 1959. El ministro de Justicia de Alessandri de ese entonces, Julio Philippi Izquierdo, defendiendo ante el Congreso el proyecto de ley que devino en la Ley 13.305, argumentaba que "si existe una materia sobre la cual es difícil legislar, es precisamente ésta" y que "por primera vez se intenta en Chile; puede ser imperfecta, pero no parece justo que se afirme que ella constituye una simple declaración demagógica".

17 Ver Domingo Valdés, Libre competencia y monopolio (Santiago: Editorial Jurídica de Chile, 2006), 90-203, en donde se reconocen ocho acepciones distintas 
Este contrataste de complejidad del derecho y simpleza de la ley no es al azar.

Se podría argumentar, por el contrario, que este contraste denota una madurez de los órganos legisladores, los que sabían que tenían que contrarrestar de alguna forma el poder privado - que invariablemente surge de una economía de mercado - a través de una fórmula flexible y abierta. Esa fórmula debía permitir que los órganos aplicadores del derecho de la competencia le pudieran ir dando contenido con sus resoluciones y fallos. Así la ley pasaba a ser una suerte de tipo delegado, que permitía y legitimaba las decisiones concretas de los órganos de libre competencia, pero en donde el legislador no se exigía algo que no podía entregar: una precisión afinada de lo prohibido. ${ }^{18}$

para "libre competencia" y además se reconoce la necesidad de que se precise tal concepto a través de la jurisprudencia. Dice: "[la libre competencia en Chile] se desenvuelve en un estadio de positivación legal todavía incipiente - en nuestra opinión éste es más precario de lo debido-y por ello se ha entregado al Tribunal Antimonopólico un cúmulo de atribuciones y decisiones que, en los hechos, excede con mucho la tarea que ordinariamente realiza un tribunal en el sistema jurídico continental". Ibídem, 23.

${ }^{18} \mathrm{Si}$ el legislador se hubiese tentado a hacer una descripción más detallada del ilícito, esa ley iba a estar condenada a una obsolescencia desde su origen. La historia de la Ley 13.305 da cuenta de la necesidad de que el ilícito sea amplio, "porque la imaginación humana es inagotable", según consta en la sesión de la Cámara de Diputados del 26 de enero de 1959. Por su parte, en la discusión de la Ley 19.911 de 2003, la Corte Suprema reconoce esta vaguedad legislativa en su oficio a la Cámara: "(...) que la experiencia internacional sobre la materia aconseja que cada caso debe ser estudiado en su propio mérito, de acuerdo con sus particularidades y complejidades, por lo que estima procedente establecer una norma amplia con ejemplos básicos, para que los integrantes del tribunal decidan en cada caso qué conducta constituye un atentado a la libre competencia" (Oficio del 20 de junio de 2002, 20). En la historia fidedigna de la Ley 19.911 de 2003 consta la opinión de la Comisión de Economía en el mismo sentido: "La mayoría de sus integrantes, desechada la idea de definir la libre competencia, se inclinó por establecerla solamente como el bien jurídico protegido, y confiar la expresión de su alcance a la doctrina y, en particular, a la jurisprudencia que emanará del Tribunal de Defensa de la Libre Competencia”. Asimismo, el profesor Jorge Streeter, invitado a dicha comisión, aseveró que "la ley de defensa de la competencia debe limitarse a describir lo substancial de las conductas monopólicas, ya que el derecho de la competencia es una disciplina que está en permanente elaboración, sobre la base de muy pocas pero fundamentales disposiciones de derecho substantivo. De aquí la necesidad de que las conductas sancionadas sean breves y simples, sin descripciones plenas de elementos normativos y subjetivos que dificultan la aplicación e interpretación de la norma, favoreciendo, finalmente, a los infractores y creando incertidumbre jurídica entre quienes observan un correcto comportamien- 
Esto no es el mundo ideal, por cierto. En un mundo ideal, uno querría que el derecho de la competencia sea menos complejo y que existiese una lista detallada y concreta de lo que no se puede hacer, y que esa lista se mantuviese en el tiempo inalterada.

$\mathrm{Al}$ menos, sabemos que tenemos un consuelo: esta misma dualidad de complejidad y simpleza, y la consiguiente decepción natural, ocurre en los países con mayor desarrollo del derecho de la competencia, tales como Estados Unidos y la Unión Europea. En esto no estamos solos ni somos originales.

Ésta es la forma como se estructura el derecho de la competencia urbi et orbi, lo que permite que las autoridades gocen de la necesaria flexibilidad para controlar el poder privado, evitando elusiones formales que harían ineficaces las aplicaciones de estas leyes.

Esa ineficacia devendría en desprestigio de la economía de mercado, en tanto el control del poder privado se haría no sólo difícil, quizá imposible.

La flexibilidad impone, por cierto, la necesidad de contar con autoridades serias, prudentes y reputadas, tanto frente al mundo político como empresarial, que tengan la energía para comprender en detalle los mercados y los hechos en discusión, el estado del arte de los estándares aplicables a la conducta en análisis, pero por sobre todo que tengan conciencia sobre los efectos de sus decisiones en la economía de mercado.

\section{CONSOLIDACIÓN INSTITUCIONAL}

Los órganos esenciales que intervienen en el derecho de la competencia en nuestro país son tres: la FNE, el Tribunal de Defensa de la Libre Competencia (TDLC) y la Tercera Sala de la Corte Suprema (CS). ${ }^{19}$

to". Ver www.bcn.cl/historiadelaley/nc/historia-de-la-ley/5814/. Por último, el Fiscal Nacional Económico precisó, en la tramitación de la Ley 20.945 de 2016 que "las leyes sobre libre competencia deben ser escuetas, dejando a la FNE y al TDLC la labor de darles sentido, por ser estas normas propias del Common Law, que es un derecho que se va formando a través de su aplicación judicial". Ver www.bcn.cl/historiadelaley/nc/historia-de-la-ley/5311/.

19 También interviene la Corte de Apelaciones en las autorizaciones para medidas intrusivas, y eventualmente otras autoridades e instancias, si así se les requiere y en sus respectivos ámbitos competenciales, como el Tribunal Constitucional, la Contraloría General de la República, el Ministerio Público y los tribunales penales cuando el Fiscal Nacional Económico haya presentado una querella por colusión. 
El sistema chileno institucional se distingue en que la decisión es tomada por un órgano judicial especializado (TDLC), que es integrado por tres abogados y dos economistas, y cuyos fallos y resoluciones son revisados directamente por la sala administrativa de la Corte Suprema. ${ }^{20}$

La FNE es el órgano persecutor y administrativo que investiga las posibles infracciones a la ley de competencia - "representando el interés general de la colectividad en el orden económico"-,${ }^{21}$ administra el sistema de control preventivo de operaciones de concentración y elabora estudios de mercado, entre otras responsabilidades.

El nuestro es un sistema exigente y con contrapesos. La exigencia viene dada por las formas propias de un litigio para los requerimientos y demandas, en el que cada evidencia tiene que ser presentada y analizada en su mérito por un panel de cinco jueces independientes. El contrapeso está en que el requerimiento no es más que la opinión de la FNE (o de un particular, en el caso de una demanda) y el fallo del TDLC está sujeto a su vez a la revisión por parte de la $\mathrm{CS} .^{22}$

${ }^{20}$ El sistema institucional chileno, que se instauró con la reforma de 2003, es similar al de Sudáfrica, aunque posterior en un par de años. En lo esencial, difiere del sistema estadounidense, en el que las decisiones son tomadas por jueces generalistas (de manera descentralizada, por la existencia de múltiples circuitos federales y de jueces estatales) y hay dos agencias encargadas del derecho de la competencia: el Department of Justice y la Federal Trade Commission. El sistema chileno, por otra parte, difiere del sistema de la Unión Europea, en el que la decisión en primera instancia es tomada por un organismo administrativo y los recursos son ante una corte generalista pero única. El sistema europeo, a diferencia del estadounidense, es centralizado y con un alto componente administrativo.

${ }^{21}$ Artículo 39 letra b) del Decreto Ley 211, de 1973, que "fija normas para la defensa de la libre competencia", disponible en http://www.fne.gob.cl/wp-content/ uploads/2010/12/DL_211_refundido_2016.pdf.

${ }^{22}$ El contrapeso al que está sujeto el TDLC frente a la CS es, a mi juicio, sano y necesario, en tanto obliga al primero a conectar el derecho de la competencia a los principios generales del sistema jurídico y a traducir la argumentación a algo inteligible para un juez generalista y con escasos conocimientos profundos en la ciencia económica. Al respecto, y dado que la CS es la última instancia, es importante contar con un análisis crítico de sus fallos por académicos independientes y por los medios de comunicación especializados, así como que el máximo tribunal exhiba una deferencia natural por los temas económicos y prácticos resueltos por el TDLC. Sobre la experticia de la CS en materia económica, es interesante transcribir el comentario del ex ministro de la CS y senador de la República Enrique Zurita, a propósito de la tramitación de la Ley 19.911: "Me desempeñé durante ocho años como presidente de la Comisión Resolutiva (...). ¿Saben Sus Señorías por qué? Porque nadie se interesaba en él, pues no era remunerado. Además, ¿qué sabe de 
Así, el que el derecho de la competencia sea vibrante y relevante en nuestro país depende de una ecología sana, conformada por los tres engranajes mencionados, en donde cada uno de ellos cumple un rol determinado, lo que permite que el sistema en su conjunto funcione bien y produzca resultados. ${ }^{23}$

Permítannos concentrarnos ahora en la FNE y en lo que con falta de pudor podríamos catalogar como un organismo consolidado y reputado por su desempeño en los últimos años.

¿Por qué la FNE ha sido y está siendo exitosa? En pocas palabras, y aunque parezca de Perogrullo, porque ha sido eficaz en aplicar la ley, en un contexto complejo, tanto del derecho de competencia en sí como del ambiente político imperante en el país, y lo ha hecho con la prudencia y sobriedad propia de una autoridad.

Veamos primero las cifras. Durante el período de abril de 2010 a agosto de 2018, la FNE presentó 37 requerimientos ante el TDLC, 19 consultas ante el mismo organismo, 37 acuerdos extrajudiciales y avenimientos, ${ }^{24} 43$ resoluciones de cambio de conducta por par-

economía un ministro de la Corte Suprema? Y para el ejercicio de ese cargo tenía que aprender, o del representante del Ministerio de Hacienda, o del de Economía, o de los decanos; y si estos últimos sabían poco, menos aprendía yo. ¿Qué hacía, entonces? Escuchaba la opinión de los otros cuatro integrantes y trataba de producir la armonía entre ellos. Sólo eso. En todo caso, estimo que no debemos seguir metiendo abogados allá. ¡Economistas! Nada más”.

${ }^{23}$ Ver el discurso del "Día de la Competencia 2017" del Fiscal Nacional Económico: "La FNE no sería un buen servicio público si no contara con excelentes contrapartes - la comunidad de abogados y economistas dedicados a la libre competencia-, ni con un excelente Tribunal de Defensa de la Libre Competencia - especializado y con jueces economistas - ni con la excelencia de la Tercera Sala de la Corte Suprema", en www.fne.cl. En el mismo sentido, discurso del "Día de la Competencia 2016", del Fiscal Nacional Económico: "El sistema de libre competencia ha funcionado (...) porque su diseño institucional castiga las opiniones infundadas, las aseveraciones livianas, las teorías sin fundamento, las frases llenas de adjetivos y carentes de verbos".

${ }^{24}$ Los acuerdos extrajudiciales y avenimientos han ido en aumento e importancia en Chile. La tradición estadounidense va en ese sentido pragmático, y los órganos persecutores evitan en lo posible enfrentarse a juicios y buscan arreglos, en la gran mayoría de las infracciones investigadas. A mi juicio, ésta es una tendencia positiva para nuestro país, por dos razones principales. Primero, porque se logran resultados concretos sobre cambios conductuales que tienen aplicación inmediata, evitando así la espera de años de un litigio. Segundo, porque libera recursos humanos de la autoridad de libre competencia y puede dedicarse a otros casos en distintos mercados. 
te del investigado, 9 resoluciones con recomendaciones de cambio normativo, 37 informes al TDLC y 25 acciones de promoción de libre competencia, incluidos los estudios de rentas vitalicias y notarios.

A partir del año 2013, tanto el TDLC como la CS han acogido el 100 por ciento de los requerimientos presentados por la FNE, superando con creces la tasa en torno al 50 por ciento que imperaba con anterioridad. Para el período 2010 a 2017, en tanto, recolectó por concepto de multas un monto superior a los 80 mil millones de pesos. ${ }^{25}$

En el mismo período se iniciaron y terminaron más de 500 investigaciones, respecto de diversas conductas y en muy distintos mercados. Todas las investigaciones terminan con una resolución firmada por el Fiscal Nacional Económico, y desde el año 2011 además se acompaña el informe interno que cada división produce a propósito de la investigación. Ambos documentos, que destilan la doctrina de la FNE, se suben a su página web y, de tiempo en tiempo, se indexan a una clasificación que facilita su búsqueda. ${ }^{26}$

La FNE logró aplicar exitosamente la reforma del año 2009 al DL 211 (Ley 20.361), que introdujo la delación compensada y las facultades intrusivas en los casos de carteles.

La FNE pudo tramitar y otorgar delaciones compensadas, tanto de empresas nacionales como internacionales, en relación con ocho solici-

${ }^{25}$ Acoger el cien por ciento de los requerimientos no implica que se otorgue todo lo pedido, y así se podría acoger el requerimiento pero imponer el pago de una multa por un monto inferior a lo solicitado en el petitorio. El monto de multas recolectado para el período 2010 a 2017 fue 80.292 millones de pesos, actualizados a pesos al 31 de diciembre de 2017. Hay que advertir, eso sí, que la FNE no es un recolector de dineros para el erario público, como lo sería un servicio de impuestos internos, sino que un defensor de la libre competencia. Ocurre que normalmente los cambios conductuales o ajustes en la forma de actuar de las empresas pueden ser más relevante que las multas. Ver Aldo González y Alejandro Micco, "Private versus Public Antitrust Enforcement: Evidence from Chile", Journal of Competition Law \& Economics 10 n. ${ }^{\circ} 3$ (2014): 691-709.

${ }^{26}$ A nuestro juicio, la transparencia en el fundamento de las decisiones de la FNE ayuda a mejorar la predictibilidad de sus futuras acciones, en tanto se explicitan públicamente los fundamentos de sus decisiones. 
tudes específicas de empresas, delaciones que sirvieron para desbaratar y sancionar a seis distintos carteles. ${ }^{27-28}$

La FNE pudo, con el eficiente y eficaz auxilio de las policías, allanar e interceptar teléfonos, con la debida autorización otorgada tanto por el TDLC como por un ministro de Corte de Apelaciones.

Todos esos allanamientos e interceptaciones fueron minuciosamente ejecutados conforme a los artículos aplicables del Código Procesal Penal y hasta ahora ningún recurso en su contra ha sido acogido por el ministro de Corte autorizante, lo que merece destacarse porque refleja la rigurosidad de la FNE y las policías en la aplicación de normas procesales penales que le eran ajenas hasta la reforma del año 2009.

La mayoría de esas medidas sirvieron para allegar evidencia que permitió sancionar a infractores de la ley de libre competencia.

Echar a andar un programa de delación compensada, que funcione, y aplicar medidas intrusivas, que no sean impugnadas, no es baladí. Se requiere planificación (en especial con la policía), prudencia (en la selección de los casos que ameritan esas medidas) y confianza (de parte de las autoridades que otorgan las autorizaciones y también respecto de las empresas que solicitan el beneficio de la delación compensada).

${ }^{27}$ Los carteles acusados por la FNE respecto de los cuales se han acogido delaciones compensadas son (i) el de compresores para refrigeradores, (ii) transporte interurbano Santiago-Curacaví, (iii) asfalto, (iv) tissue, (v) navieras y (vi) medicamento para ampollas. En el cartel del tissue y de navieras se recibieron delaciones compensadas de dos empresas. Es interesante hacer notar que hay casos que involucran empresas internacionales (como el de compresores) y otros, nacionales (como el de transporte interurbano). Dentro de las empresas nacionales que obtuvieron el beneficio de la delación compensada figuran dos grupos económicos chilenos de importancia, lo cual denota un éxito en la implementación del programa de delación compensada. Las sentencias condenatorias del TDLC respecto del caso tissue, navieras y medicamentos para ampollas fueron reclamados ante la CS y aún no han sido resueltos por el máximo tribunal.

${ }^{28}$ El año 2009 la FNE redactó una guía de delaciones compensadas para dar certezas a sus postulantes, guía que luego fue reemplazada por una nueva versión en el año 2017. El documento de 2017 fue sometido a tres procesos de consulta pública y recoge los comentarios, sugerencias y aportes de diversos organismos públicos y privados, tanto nacionales (como el Colegio de Abogados de Chile) como internacionales (como la American Bar Association, la International Bar Association y el Departamento de Justicia de Estados Unidos). Ver www.fne.gob.cl/guiainterna-sobre-delacion-compensada-en-casos-de-colusion. 
Ambos institutos, la delación compensada y las medidas intrusivas, son algo ajenos a la tradición jurídica chilena: que se exculpe completamente a quien confiesa y que se utilicen medidas intrusivas como la interceptación telefónica por una infracción de naturaleza económica.

Explicar la delación compensada no fue fácil. Exculpar a quien ha reconocido una infracción no se considera, en principio, justo. Pero ésa es una crítica cortoplacista y equivocada, por varias razones. Primero, resulta evidente que hay que darle incentivos al delator para que se delate. El principal incentivo es que quede completamente liberado de sanciones pecuniarias y de la posibilidad de tener que enfrentar un eventual proceso penal. Los incentivos para autodenunciarse van adquiriendo mayor importancia a medida que los partícipes del cartel logran administrarlo sin dejar o dejando poca evidencia, lo que suele ocurrir cuando los empresarios toman mayor conciencia del derecho de competencia. Segundo, un programa efectivo de delación compensada permite inhibir futuros carteles o desbaratar los que están operativos. Debido a las limitaciones naturales de toda autoridad, la disuasión es vital. Tercero, el delator y los otros partícipes del cartel deben compensar a las víctimas del cartel, y esa compensación justa se facilita precisamente por su delación.

Otra expresión de la madurez de la FNE se refiere a la planificación desplegada por este organismo para acometer una reforma legal (la Ley 20.945), la cual fue aprobada con amplio apoyo de los diversos sectores políticos del Congreso. ${ }^{29}$

Es interesante anotar en qué consistió esa planificación y cómo gracias a ella el debate, la discusión y el resultado fueron los esperados, y no hubo grandes sobresaltos ni improvisaciones, lo que contrasta con otras reformas que se hicieron en esos años.

La planificación consistió en contar con un diagnóstico claro de lo que se requería reformar, en ir mostrando en el tiempo esa necesidad a propósito de casos concretos y en encargar estudios externos que reafirmaran el diagnóstico del problema y sugirieran soluciones.

${ }^{29}$ La Ley 20.945 fue aprobada por unanimidad en el Congreso, salvo respecto al artículo que establecía que la investigación del Ministerio Público sólo podía iniciarse por querella del Fiscal Nacional Económico una vez que estuviese a firme la sentencia del TDLC que condena al cartel. El Ministerio Público, en cambio, prefería (al menos eso manifestó al final del proceso legislativo) que pudiese iniciar investigaciones penales a su discreción, con o sin querella del Fiscal Nacional Económico. 
El diagnóstico hacia adentro de la FNE era bastante claro: las sanciones por infracciones —en especial carteles - no eran disuasivas, ${ }^{30} \mathrm{y}$ Chile requería un sistema de control de operaciones de concentración que fuese predecible y ordenado. ${ }^{31}$

La presentación del requerimiento del cartel de pollos aceleró la discusión y el primer gobierno del Presidente Piñera formó una comisión de estudio de la legislación chilena, liderada por el economista Francisco Rosende, que entregó su informe el año 2012. ${ }^{32}$

La sensación de que se requería una reforma en el sistema de operaciones de concentración se acrecentó en parte gracias a las actividades de la FNE. Varias de las acciones de la FNE ocurrían por primera vez en el sistema de libre competencia chileno e iban despertando una conciencia sobre la necesidad de un cambio legal.

Lo primero que habría que destacar es el rechazo de un prospecto de joint venture de dos empresas líderes en el mercado de la leche por parte de la FNE, lo que se alejaba de la postura tradicional del órgano persecutor de focalizarse en las condiciones de una operación y evitar una solicitud frontal de rechazo. ${ }^{33}$ Además, la FNE por primera vez

${ }^{30}$ Como un botón de muestra de la falta de disuasión de las sanciones, podemos citar las declaraciones del dueño de una importante empresa productora de pollos condenada por colusión a pagar la máxima multa del sistema chileno, que ascendía a alrededor de US\$ 30 millones: "Si hay multas las vamos a pagar, pero las multas dan lo mismo. Es el hecho, el nombre (...)". El Mercurio, 12 de octubre de 2014. Las cursivas son nuestras.

${ }^{31}$ Chile, a diferencia de Estados Unidos y Europa, se había negado a aprobar una ley que controlara preventivamente las operaciones de concentración, esto es, antes de que se materialicen, y mantenía un sistema de control voluntario desde el año 1959. La naturaleza voluntaria obligaba a la autoridad a impugnar operaciones ya concretadas, lo que era jurídicamente difícil por la prueba de los efectos potenciales de la operación. Si la autoridad administrativa hubiese logrado convencer al TDLC de la reprochabilidad de la operación, surgía la dificultad de tener que volver a la situación existente antes de la operación, lo que coloquialmente se conoce en el mundo anglosajón como "unscrambled the eggs". Además, el DL 211 no contenía ninguna regulación específica sobre las fusiones, y el sistema de consulta ante el TDLC era inapropiado para conducir una discusión razonable sobre las operaciones de concentración por su tinte litigioso, aunque se tratara, en el papel, de procedimientos no contenciosos.

32 Disponible en www.economia.gob.cl/wp-content/uploads/2012/07/INFORME-FINAL-ENTREGADO-A-PDTE-PINERA-13-07-12.pdf.

33 Ver el informe de la FNE sobre operación Nestlé-Soprole en http://www. fne.gob.cl/fne-se-opone-a-la-operacion-consultada-por-soprole-y-nestle/. 
formuló una consulta sobre una operación de compra en el mercado de los supermercados, utilizando una facultad de la reforma del 2009. ${ }^{34}$ También se empezó a emplear por la FNE el mecanismo de los acuerdos extrajudiciales, para aprobar las condiciones negociadas entre la FNE y las empresas que buscaban concentrarse. ${ }^{35}$ Por último, y también por primera vez, la FNE presentó un requerimiento por una operación de concentración materializada sin haberse consultado en el mercado de los locales para exhibición de cine. ${ }^{36}$

Con un sentido realista, pero con la firme intención de avanzar en este tema, la FNE aprobó una guía de control de operaciones de concentraciones el año 2012, con la que ofrecía un procedimiento ordenado, en etapas y con plazos perentorios, para quienes voluntariamente quisiesen conocer la opinión de la FNE respecto a una operación concreta. Esta opinión obviamente no amarraba ni al TDLC ni a la CS, pero al menos le aseguraba al consultante conocer de antemano el parecer de la FNE bajo un procedimiento de negociación horizontal y así evitar la sorpresa de una posible consulta de la FNE ante el TDLC. ${ }^{37}$

La FNE encargó tres estudios a reputados organismos extranjeros, previo al inicio del proceso legislativo de reforma al DL 211. Un estudio se refería a las sanciones aplicables en Chile y su real disuasión, a cargo de connotados abogados y economistas vinculados al University

${ }^{34}$ Ver consulta de la FNE por la compra por parte de D\&S a Alvi en http:// www.fne.gob.cl/fne-consulta-ante-el-tdlc-compra-de-supermercados-alvi-por-partede-ds/.

${ }^{35}$ Ver acuerdos extrajudiciales en sitio del TDLC, sección "Expedientes", subsección "Acuerdos Extrajudiciales".

36 Ver requerimiento por una operación de concentración en cines en www. fne.gob.cl/wp-content/uploads/2012/06/requ_01_2012.pdf. La operación era una concentración horizontal entre Hoyts y Cinemundo, dos cadenas de cines con presencia en nuestro país. La FNE buscaba que se produjese una desinversión en tres localidades en donde la concentración del nuevo conglomerado era alta. Finalmente, las partes llegaron a un acuerdo.

${ }^{37}$ Disponible en www.fne.gob.cl/wp-content/uploads/2012/10/Guia-Fusiones. pdf. Esta guía, que fue redactada luego de revisar en profundidad las guías existentes en el extranjero, fue sometida a un proceso de consulta pública, por el cual se recibieron comentarios de actores nacionales y extranjeros. No es de extrañar que la guía presente evidentes similitudes con la Ley 20.945 de 2016, la que precisamente instauró un sistema de control obligatorio de operaciones de concentración. 
of College de Londres. ${ }^{38}$ Otro era sobre el control de operaciones de concentración a la OCDE de $2014^{39}$ y un tercero, también a la OCDE, sobre estudios de mercados en Latinoamérica de $2015{ }^{40}$

La Ley 20.945, de 2016, entonces, introdujo un régimen de sanciones disuasorio, un sistema de control preventivo de operaciones de concentración y la facultad para realizar estudios de mercados, además de otras reformas. Con estas modificaciones el escenario regulatorio cambió radicalmente, y Chile se acopló a las normativas de los países más adelantados.

Antes de la reforma de 2016, las sanciones monetarias tenían un techo de aproximadamente US\$ 30 millones y no había sanción penal por casos graves de colusión. Ese techo beneficiaba especialmente a las grandes empresas. Estas sanciones no eran disuasivas, y se podía decir que podía ser un "buen negocio" para las empresas infringir la ley, teniendo en consideración los enormes beneficios que se pueden derivar de un cartel o un abuso de posición dominante.

Ahora las sanciones monetarias pueden llegar al 30 por ciento de las ventas del infractor o el doble del beneficio, y se estableció una sanción penal de hasta diez años de privación de libertad para el caso de carteles para fijar precios, limitar la producción, repartir zonas o cuotas o afectar el resultado de licitaciones públicas. ${ }^{41}$

38 Disponible en www.fne.gob.cl/2014/11/12/estudio-sobre-multas-en-sedede-libre-competencia/. Este estudio sobre multas en sede de libre competencia fue encargado al Centro de Derecho, Economía y Sociedad del University College London (UCL), y confeccionado, entre otros, por los profesores Ioannis Lianos, Florian Wagner Von Papp y Frederic Jenny. El estudio analizó el régimen sancionatorio de diversos países líderes en derecho de la competencia y lo comparó con el chileno, concluyendo que el sistema chileno de sanciones no era disuasivo y que por ende requería una modificación.

${ }^{39}$ Ver Informe del Secretariado de la OCDE "Evaluación del régimen de control de concentraciones en Chile", del año 2014, disponible en www.oecd.org/daf/ competition/Chile\%20merger\%20control_ESP_nov14.pdf. Este estudio fue solicitado por el Ministerio de Economía del primer gobierno del presidente Piñera y recibido por el Ministerio de Economía del segundo gobierno de la Presidenta Bachelet, lo cual refleja que se trataría de una política de Estado.

${ }^{40}$ Ver el "Informe para el año 2015" de la OCDE: "Competition and Market Studies in Latin America", disponible en www.oecd.org/daf/competition/competencia-y-estudios-de-mercado-en-america-latina por ciento202015.pdf.

${ }^{41}$ Ver artículo 62 del DL 211, de 1973. 
Luego de una tradición de más de 50 años, el país cambió de un sistema voluntario de revisión de las operaciones de concentración hacia uno de notificación previa obligatorio bajo una tramitación esencialmente administrativa. El nuevo sistema permite analizar las operaciones de concentración que superen ciertos umbrales antes de que se perfeccionen, y evaluar, dentro de plazos acotados, sus riesgos y eficiencias. ${ }^{42}$

También la nueva ley le otorgó a la FNE facultades para elaborar estudios de mercados con información de privados y de órganos públicos.

La FNE ha logrado, hasta ahora, aplicar exitosamente la reforma del año 2016 al DL 211, mediante la Ley 20.945.

El año 2017 la FNE dictó, luego de un proceso de consulta pública, cinco guías en materia de fusiones: una sobre jurisdicción; otra sobre remedios o medidas de mitigación; una tercera sobre aplicación de los umbrales, y dos más sobre los documentos que deben presentarse, en versión completa y simplificada. ${ }^{43}$

El contenido de algunas de estas guías fue revisado por abogados extranjeros con experiencia en notificaciones, el Colegio de Abogados de Chile, autoridades estadounidenses y por la International Bar Association y la American Bar Association.

Además, la FNE contribuyó con el Ministerio de Economía en la redacción del reglamento a la Ley 20.945, el cual fue publicado dentro del plazo establecido en la ley y antes de entrar en vigencia el sistema de control.

${ }^{42}$ El proyecto de ley presentado por el gobierno el año 2015 establecía que la determinación de los umbrales era responsabilidad del Ministerio de Economía. Sin embargo, el Congreso prefirió que esa determinación fuese hecha por la FNE, y así quedó en la Ley 20.945. Para determinar los valores de los umbrales, la FNE se basó en un informe económico que siguió los lineamientos de la International Competition Network y de la OCDE en la materia. Este informe fue sometido a comentarios de los economistas externos Claudio Agostini, Ronald Fischer, Aldo González, Juan Pablo Montero y Tomás Rau, los cuales se manifestaron a favor de la metodología y de los umbrales propuestos en el informe. Ver informes en www. fne.gob.cl/umbrales-operaciones-de-concentracion/.

${ }^{43}$ Ver Felipe Irarrázabal y Felipe Cerda, "Establecimiento de un sistema de control previo de operaciones de concentración en Chile: orígenes, implementación y desafíos", en Comentarios a la Ley de Defensa de la Competencia, dirigido por Demetrio A. Chamatropulos, Pablo Trevisán, Miguel del Pino (Buenos Aires: La Ley, 2018). La guía de remedios orienta a las partes de una operación de concentración sobre las medidas de mitigación que pueden ofrecer a la FNE. 
En junio del año 2018 se cumplió un año del funcionamiento del sistema de control de operaciones de concentración. De un total de 58 operaciones presentadas, ya se habían resuelto 43, de las cuales 36 fueron aprobadas pura y simplemente en fase 1 (con un plazo de promedio de 18 días), 6 fueron aprobadas con medidas (en un plazo de 66 días promedio) y 1 fue rechazada.

Al cumplirse seis meses de la vigencia del mecanismo de notificación, la FNE realizó una encuesta entre abogados de estudios jurídicos que asesoraron a las partes notificantes en procesos de notificación de operaciones de concentración, y ésta arrojó un balance positivo. ${ }^{44}$

Además, se implementó un mecanismo digital para recibir las notificaciones por participaciones cruzadas, según lo exige el artículo 4 bis del DL 211, y se dieron lineamientos sobre cómo y cuándo cumplir dicha obligación, a través del formulario respectivo. ${ }^{45}$

En materia de estudios de mercado, se procedió a conformar el equipo profesional encargado de realizar dichos estudios, se aprobó una guía para su elaboración, ${ }^{46}$ que sigue las mejores prácticas de la

${ }^{44}$ Las encuestas se realizaron entre junio y noviembre de 2017 y se encuentran disponibles en: www.fne.gob.cl/wp-content/uploads/2018/03/Informe-Resultados-Encuesta-Fusiones.pdf. El 76,4 por ciento de los encuestados calificó con nota 6 o superior (de un máximo de 7) la implementación del nuevo régimen de control de operaciones de concentración. A su vez, el 87 por ciento de los encuestados calificó como muy pertinente o pertinente la información solicitada por la FNE una vez iniciada la investigación.

45 Disponible en www.fne.gob.cl/wp-content/uploads/2016/12/FormularioParticipaciones-minoritarias-v1.9.pdf. Es interesante consignar que la preocupación por el tema de las participaciones cruzadas y por el interlocking surgió de la misma FNE, la que hizo un estudio sobre el tema (años antes del proyecto de ley de 2016), que incorporó un informe de un abogado estadounidense sobre la realidad regulatoria de ese país. Ver documento "Participaciones minoritarias y directores comunes entre empresas competidoras", de noviembre de 2013, disponible en http://www. fne.gob.cl/wp-content/uploads/2013/11/Participaciones-minoritarias.pdf. Ver "Combatting Anticompetitive Interlockings: Section 8 of the Clayton Act as a Template for Chile and Similar Emerging Economies", de Michael Jacobs, de 24 de octubre de 2013, disponible en http://www.fne.gob.cl/wp-content/uploads/2013/11/ClaytonAct-Section-8.pdf y "U.S. Antitrust Enforcement Involving Minority Shareholdings", del mismo autor, de 31 de agosto de 2013, disponible en http://www.fne. gob.cl/wp-content/uploads/2013/11/Minority-Shareholding-in-the-US.pdf.

46 Disponible en www.fne.gob.cl/wp-content/uploads/2017/10/Guia_Estudios_Mercado_Final_oct2017.pdf. 
OCDE, y se iniciaron los análisis sobre rentas vitalicias, notarios y medicamentos, de los cuales se alcanzó a terminar los dos primeros. ${ }^{47}$

Además, la FNE publicó una guía que precisa las situaciones que ameritarían la interposición de una querella penal, realizada con el apoyo de asesores externos y luego de recibir comentarios a un borrador inicial, tanto de abogados chilenos como extranjeros. Esta guía busca disminuir los espacios de discrecionalidad y señalizar al mercado la visión de la FNE sobre la aplicación de la ley, con mucha antelación a su aplicación efectiva. ${ }^{48}$

La consolidación de la FNE también se refleja en los resultados que arrojaron las encuestas sobre percepción confeccionadas por la auditora Deloitte a los abogados que se dedican al derecho de la competencia en Chile. El año 2012, dicha auditora entrevistó personalmente a tales abogados sobre temas de percepción y desempeño de la autoridad de libre competencia. La gran mayoría de los abogados accedió y el informe final se hizo público, con los datos agregados. Los resultados que la FNE obtuvo fueron en general buenos, y el ejercicio se repitió los años 2014 y 2016, con el objetivo de observar las tendencias. ${ }^{49}$

47 Ver el informe sobre rentas vitalicias en www.fne.gob.cl/wp-content/ uploads/2018/02/Informe-Final-EM01.pdf y ver informe sobre notarios en www. fne.gob.cl/wp-content/uploads/2018/07/Informe-Final-optimizado.pdf. El informe sobre medicamentos debiera publicarse a fines del 2019, según se consigna en el calendario propuesto por la FNE en www.fne.gob.cl/wp-content/uploads/2018/04/ Minuta_EMO3_2018.pdf.

${ }^{48}$ Disponible en www.fne.gob.cl/wp-content/uploads/2018/06/Gu\%C3\%ADade-Querellas-final-definitiva.pdf. Esta guía se elaboró con la asesoría de destacados abogados penalistas y administrativistas nacionales, y también se recibieron comentarios de la American Bar Association (ABA), Comisión Federal de Competencia Económica de México (Cofece), International Bar Association (IBA) y del Fiscal Nacional del Ministerio Público. También se refleja la planificación con que opera la FNE en los temas importantes. La aplicación de la ley se hará en varios años más porque la decisión de querellarse o no que debe adoptar el Fiscal Nacional Económico debe tomarse una vez que se haya dictado una sentencia, que esté a firme, por parte del TDLC, respecto a hechos que hayan ocurrido con posterioridad a la aprobación de la ley del 2016, de conformidad con lo que exige la Constitución Política de la República de Chile.

${ }^{49}$ Hasta donde sabemos, la FNE es la única agencia de competencia en el mundo que ha hecho este ejercicio en forma continua, y esperamos que se siga haciendo porque es una forma eficiente de recoger el parecer de las contrapartes sobre cómo está operando el sistema, y en especial la autoridad administrativa. La agencia que primero lo hizo fue la OFT de Inglaterra el año 2007, pero no repitió el ejercicio. La encuesta Deloitte está constituida por cerca de 50 preguntas. Se interroga, por ejemplo, por el nivel del análisis técnico de la FNE, su independencia, resguardo a la confidencialidad, grado de previsibilidad y rigurosidad. Los estudios están disponibles en http://www.fne.gob.cl/estudios-de-percepcion-deloitte/. 
Es pertinente analizar a continuación los principales objetivos y valores que guiaron la actuación de la FNE: independencia, enfoque selectivo, tono técnico, conformación de equipos de trabajo e internacionalización. Para cada una de estas orientaciones se adoptó una estrategia que hizo posible su concreción en el modelo vigente.

\section{INDEPENDENCIA}

La primera estrategia seguida por la FNE fue poner especial hincapié en la independencia, tanto respecto de las empresas como del gobierno y reparticiones públicas. Esto fue considerado siempre como primera prioridad, como algo intransable. La dirección de la FNE era la que se ocupaba de este asunto, de manera que los equipos de trabajo tuvieran la tranquilidad necesaria para hacer el trabajo con criterios estrictamente técnicos. ${ }^{50}$

Fue una primera prioridad porque veíamos que había una conexión y un círculo virtuoso entre independencia, espesura técnica, confianza y predictibilidad. Si las decisiones dependían enteramente de argumentos y razones técnicas era porque no había interferencia de ningún tipo, y esa falta de interferencia se conseguía precisamente mediante la independencia. La espesura técnica, a su vez, permite mejorar la confianza y predictibilidad del organismo técnico, que queda así liberado de los vaivenes y azares propios del juego político.

Asimismo, la independencia está conectada con la planificación. Si el organismo es independiente, ese organismo va fijando sus tiempos, sus prioridades y sus modos, y no debe responder a los apuros y las ansiedades propias del mundo político. ${ }^{51}$

${ }^{50}$ La dirección de la FNE estaba compuesta por el fiscal, el subfiscal y la jefa de relaciones institucionales, y la encargada de prensa. No era un organismo que estuviera así ideado en la ley, sino una organización interna que se adoptó y que se facilitaba con la cercanía física de las oficinas respectivas. Resulta interesante anotar que los subfiscales de estos últimos ocho años eran funcionarios que habían sido contratados bajo administraciones anteriores de la FNE (Jaime Barahona y Mario Ybar), al igual que la jefa de relaciones institucionales (Mónica Salamanca), lo que corrobora la sana continuidad institucional.

51 Ver el discurso del "Día de la Competencia 2017". Disponible en http://www.fne.gob.cl/wp-content/uploads/2017/11/Discurso-Fiscal-Felipe-Irarr $\%$ C3\%A1zabal-2017.pdf. 
Por ley, la FNE es independiente de todo organismo, servicio o autoridad. Esto se dice dos veces en el DL 211, y no se admite excepción alguna. $^{52}$

Y se dice nuevamente una tercera vez cuando la ley ordena que el fiscal defienda los intereses que le están encomendados, o sea los intereses públicos en el orden económico de libre competencia, "en la forma que estime arreglada a derecho, según sus propias apreciaciones". ${ }^{53}$

Así, tanto el texto como el sentido de la ley es claro, y no hay doblez alguno.

Esta independencia se refuerza con la existencia de un período fijo de duración del cargo (cuatro años renovables por otros cuatro más) y el mecanismo de destitución del Fiscal Nacional Económico. Para que opere una destitución, a partir de la reforma del año 2009, debe concurrir una causal legal ("negligencia manifiesta en el ejercicio de sus funciones"), no siendo suficiente la mera voluntad de quien lo eligió; esto es, el Presidente de la República. Pero quizás más importante es el resguardo procesal para dicha destitución, que tiene que iniciarse con una petición del ministro de Economía, luego debe emitirse un informe favorable del pleno de la Corte Suprema que corrobore que se cumple

52 El artículo 33 del DL 211 dispone: "La Fiscalía Nacional Económica será un servicio público (...) independiente de todo organismo o servicio, sometido a la supervigilancia del Presidente de la República a través del Ministerio de Economía, Fomento y Reconstrucción". Esa supervigilancia debe circunscribirse a la inspección de asuntos administrativos de la FNE, y al proceso de remoción en caso de negligencia manifiesta, a asuntos de remuneración y planta y a toda otra cuestión administrativa, sin alcanzar en forma alguna a las atribuciones reseñadas en el artículo 39 del DL 211, de 1973, las que son exclusivas y privativas del Fiscal Nacional Económico. Por su parte, el encabezado del artículo 39 del mismo cuerpo legal establece: "El Fiscal Nacional Económico, en el ejercicio de sus funciones, será independiente de todas las autoridades y tribunales ante los cuales actúe". Las cursivas son nuestras.

${ }^{53}$ El mismo artículo 33, en su encabezado, establece que: "Podrá, en consecuencia, [el Fiscal Nacional Económico] defender los intereses que le están encomendados en la forma que estime arreglada a derecho, según sus propias apreciaciones". La cursiva es nuestra. Ver Patricio Bernedo, Historia de la libre competencia en Chile, 1959-2010 (Santiago: Fiscalía Nacional Económica, 2013): “Como se verá más adelante, este artículo [39 encabezado] se transformó en el verdadero fundamento de la autonomía y poder de los fiscales económicos que, dependiendo de los rasgos de personalidad del fiscal en ejercicio, sirvió para resistir todo tipo de presiones". 
la causal de negligencia manifiesta, para terminar con la decisión de destitución por parte del Presidente de la República. ${ }^{54}$

Puede ocurrir, sin embargo, que el derecho sea superado por la realidad, y la aplicación de una norma legal, por un sinnúmero de subterfugios o resquicios, sea débil o inexistente - o sea, letra muerta - en situaciones concretas en las que hay intereses poderosos en juego, como suele ocurrir en los casos de libre competencia.

El libro del historiador Patricio Bernedo sobre la libre competencia en Chile da cuenta de las dificultades que han enfrentado anteriores fiscales nacionales económicos respecto a la independencia.

Rodrigo Asenjo, quien fuera Fiscal Nacional Económico durante los años 1994 a 2000, relata su experiencia y parecer en los siguientes términos:

Quiero dejar constancia que, en 6 años, jamás recibí un llamado del Presidente de la República. Tampoco recibí un mensaje del Presidente vía algún ministro de Estado, pero sí recibí muchas llamadas de diversos personeros, a los cuales había que darles lectura del artículo 24 del DL 211, que establecía la autonomía absoluta del servicio y del Fiscal. Ahi se dice que el Fiscal actúa según sus propias convicciones. Reconozco que eso lo hice en muchas ocasiones, con muchos funcionarios, parlamentarios, jefes de otros servicios y empresarios. Ahora, el tema de las presiones opera, en la medida que uno sea presionable. Y yo -me siento muy orgulloso de lo que voy a decir-, no me considero un tipo presionable. Podría hablar un día entero respecto de las presiones, pues de verdad tuve muchas, pero bueno, esto va con

${ }^{54}$ Ver artículo 33 del DL 211, modificado por la reforma del 2009. A mi juicio, es importante que el inicio del procedimiento de destitución no quede entregado a instancias enteramente políticas, como sería, por ejemplo, un número determinado de diputados de la República, como ocurre con el cargo de Fiscal Nacional del Ministerio Público. Esa fórmula, según veo, puede provocar un efecto negativo por el solo hecho de que se inicie un procedimiento de destitución, aunque luego sea desestimado por la Corte Suprema. Durante la discusión de la Ley 20.945, algunos diputados de la Comisión de Economía de la Cámara de Diputados intentaron modificar la ley para permitir que el proceso de destitución del Fiscal Nacional Económico fuese iniciado por 10 diputados, pero la idea afortunadamente no prosperó. Este mecanismo de destitución no estaba consagrado así en el proyecto de ley. Fue introducido en la Cámara de Diputados por una indicación del Ejecutivo. Inicialmente, el Consejo de Alta Dirección era el órgano que emitía el informe favorable para la destitución, pero luego en el Senado se reemplazó por la Corte Suprema. 
la personalidad de cada uno y con la estructura de pensamiento que uno tiene, y la trayectoria que uno tiene. Este cargo se puede ejercer con independencia, siempre y cuando se quiera ejercerlo así, pues tiene las atribuciones para hacerlo, pero debe quererlo. Y yo creo que eso es suficiente. Eso está en la persona. ${ }^{55}$

Francisco Fernández, Fiscal Nacional Económico desde el año 2000 al 2001, decidió renunciar debido a las presiones, según se desprende de sus propias palabras:

Ahí hubo presiones muy intensas, un fenómeno de lobby, que al no estar regulado daba pábulo para todo tipo de maniobras. ${ }^{56}$ (...) Cuando asumí, se me prometió un apoyo político que no terminó dándose en los hechos. Dada la naturaleza de ente descentralizado de la Fiscalía, era muy importante contar con un respaldo del Ejecutivo para disponer de libertad de juicio. Era un apoyo en términos de no interferir y eso no se dio como yo hubiera deseado y como se me dijo por el Presidente Lagos cuando me pidió asumir esta tarea en su gobierno. Las presiones eran múltiples, yo fui testigo de algunas francamente inaceptables y yo preferí entonces dar un paso al lado. Las presiones se ejercían también sobre los miembros del Tribunal [Comisión Resolutiva]. En el caso de los directores de servicio, yo fui testigo de instrucciones perentorias dadas para que votaran en un sentido determinado. Cuando se decía que las instituciones funcionaban, uno se preguntaba, bueno ésta también debería funcionar. ${ }^{57}$

Lo anterior no debiera sorprendernos. La textura abierta del derecho de la competencia - similar a una esponja que puede absorber distintas políticas públicas — sumada a su armamento sancionatorio de alto calibre y al costo reputacional natural de cualquier inicio de un procedimiento hacen especialmente atractiva su instrumentalización para fines distintos al derecho de la competencia.

Un ejemplo de esa instrumentalización, por cierto, excepcionalísimo, viene del país que inventó el derecho de competencia. En 1971, el

\footnotetext{
${ }^{55}$ Bernedo, Historia ..., 148. Los énfasis son nuestros.

${ }^{56}$ Ibídem, 152. La cursiva es nuestra.

${ }^{57}$ Ibídem, 157. La cursiva es también nuestra.
} 
entonces Presidente de Estados Unidos, Richard Nixon, amenazó a las cadenas de televisión norteamericanas $\mathrm{ABC}, \mathrm{NBC}$ y CBS con iniciar un juicio de competencia, si tales cadenas no suavizaban sus críticas al gobierno, según dan cuenta las grabaciones de la Casa Blanca que recogen frases textuales de Nixon en tal sentido. ${ }^{58}$

En esta materia, tenemos que admitir que nuestra experiencia de más de ocho años al mando de la FNE fue muy positiva. No nos vimos expuestos a experimentar malos ratos por parte de personeros de gobierno o ejecutivos de empresas que presionaran en uno u otro sentido. Tampoco recibimos mensajes o indirectas desagradables que buscaran poner en riesgo nuestro proceso de toma de decisiones.

La independencia se da naturalmente con las empresas y entidades privadas, en tanto sujetos de investigaciones. La FNE tiene su foco en el interés general, en tanto las empresas se centran en su interés particular. Algo distinto devendría en corruptela. El desafío de la FNE con el poder privado, más que con la independencia, se centra en la razonabilidad, no discriminación e igualdad de trato que se les debe dar a las empresas, que deriva del análisis desapasionado de los hechos que van apareciendo en cada una de las investigaciones.

Las empresas necesitan, eso sí, tener certeza de que la autoridad de libre competencia es independiente de las máximas autoridades del país, porque de lo contrario el lobby de ellas se encauza a través de tales autoridades. $^{59}$

Así, el tema de la independencia adquiere real magnitud en relación con otras autoridades, y en especial con las máximas autoridades de gobierno.

Hipotéticamente, las interferencias más graves que podrían provenir del gobierno de turno podrían referirse a sugerencias de aperturas de una determinada investigación en un mercado específico sin haber mérito para ello; a cerrarla sin que concurran razones técnicas suficientes; a solicitar conocer las investigaciones que la FNE está realizando y que tienen el carácter de confidenciales; a exigir conocer de antemano

${ }^{58}$ Ariel Ezrachi, “Sponge”, Journal of Antitrust Enforcement 5 (2017): 56.

${ }^{59}$ Como ya se comentó, la encuesta Deloitte de percepción a los abogados chilenos de libre competencia mide, entre otros aspectos, el grado de independencia de la FNE. Los resultados fueron los siguientes, en una escala de 1 a 7 , lo que refleja una tendencia positiva en el tiempo: nota 4,5 para el año 2012, nota 5,8 para el año 2014 y nota 6,4 para el año 2016. 
los requerimientos o presentaciones que la FNE hará, o, en general, a interferir de cualquier forma con alguna diligencia particular en una investigación o juicio.

Como ya dijimos, al menos en nuestra experiencia y habiendo ejercido el cargo durante el período de dos presidentes de la República de distinto color político (y sus consiguientes seis ministros de Economía), no sufrimos ninguno de los embates arriba anotados. Ni de cerca. Esto es algo que la misma Fiscalía ha ido ganando en el tiempo, gracias a los sacrificios de los anteriores fiscales, pero también a la seriedad de las máximas autoridades del país y su confianza en los organismos técnicos.

Ese activo de la FNE debe mantenerse a futuro, a sangre y a fuego, y es su sello más valioso, si se pretende que su reputación y consolidación se mantengan.

La independencia tiene, a mi juicio, un componente importante de carácter de las personas que ejercen el cargo. La disposición mental es que no se va a otorgar favor alguno a nadie. La otra cara de la moneda es que no se puede pedir favor a nadie. Así, la independencia deviene en soledad, tanto respecto al gobierno, como a los partidos políticos, al Congreso, a las otras autoridades y, por cierto, a las empresas que se investigan.

Además de esa soledad, hay otro componente sicológico que es importante y que se refiere al control personal de la ambición, que tiene una conexión con la libertad en las actuaciones que requiere el cargo. A nuestro juicio, idealmente, el Fiscal Nacional Económico no debería ambicionar otro cargo público, menos en la arena política, de manera que el cargo no sea un trampolín para futuras nominaciones o designaciones. Esa falta de ambición otorga la libertad que se necesita para no caer en la tentación de complacer, en especial a las máximas autoridades del país.

La falta de complacencia deviene en frialdad (sin que eso implique perder la natural cordialidad), tanto con el mundo público como con el mundo privado. No parece aconsejable dar espacio a un ambiente más relajado y de cercanía. Es necesario ser, como sabiamente se nos aconsejó, "descariñado". ${ }^{60}$

${ }^{60}$ En mi primera reunión protocolar con el en ese entonces presidente de la Corte Suprema, Milton Juica, le pregunté sobre qué consejos me daría. El primero a que hizo referencia es que fuese "descariñado", lo que siempre recordé durante el ejercicio del cargo. 
La independencia también tiene una conexión con el tema de los conflictos de intereses. Si se quiere ser independiente, no puede haber conflicto alguno de intereses.

A nuestro juicio, en ese tema hay que ser muy cuidadoso. Apenas asumimos, aprobamos un reglamento interno en la FNE, que se cumplió a nuestro entender cabalmente. ${ }^{61}$ Ahí se aclaraba que el inhabilitado no iba a participar en reuniones internas en las que se discutiera sobre el caso en que se inhabilitó, no iba a participar en audiencias, no podría revisar el expediente del caso, e incluso sería impedido de tener acceso computacional a las carpetas de archivos del caso. Además, se establecía un mecanismo de notificación por escrito de las inhabilidades.

Así, en los casos en que un funcionario de la FNE presentaba conflicto de interés, perdía toda conexión con el caso, y el asunto era liderado total y completamente por un equipo sin conflicto alguno, quienes con entera libertad e independencia decidían sobre lo que se tenía que hacer o no hacer.

En suma, la FNE ha gozado durante estos años de independencia real y efectiva, lo que le ha permitido decidir con criterios técnicos, aumentar la predictibilidad de sus actuaciones, incrementar la confianza de los gobernados y autoridades, y proyectar tareas de largo plazo.

\section{SELECCIÓN}

Un segundo pilar esencial del modelo de la FNE fue ser selectivos en relación con los casos que investigamos y respecto a las herramientas a utilizar en caso de infracciones.

La selección significa que hay que elegir, y elegir significa que hay que dejar de investigar asuntos que parecen de segundo orden, asumiendo un costo alternativo. También significa que hay que seleccionar la herramienta proporcional y justa para hacerse cargo del grado de intensidad que pueden presentar las distintas reprochabilidades.

En principio, la tendencia natural de la autoridad es a abarcar lo más posible, y supone que no se tiene limitación alguna de recursos ni de tiempo. Nosotros hicimos justo lo contrario, y establecimos una es-

61 Ver "Instructivo sobre aplicación del principio de abstención e inhabilidades en la Fiscalía Nacional Económica”, en www.fne.gob.cl/wp-content/ uploads/2017/10/reso_236_2010-1.pdf. 
trategia que implicaba que había que tener buenas razones para iniciar una investigación, sea por oficio o por denuncia. ${ }^{62}$

Cuando llegamos a la FNE, el stock de investigaciones llegaba a alrededor de 150. De inmediato consideramos que ese número era difícil de manejar, y nos propusimos bajarlo, en especial si se quería investigar a fondo algunos mercados complejos y en un tiempo acotado.

Un problema secundario, que es clave en las investigaciones de mercados de por sí dinámicas, son los tiempos que se requerían para cada investigación. Mientras más investigaciones, más lento el proceso para terminarlas. Si, en cambio, acotábamos el número de investigaciones, íbamos a poder concentrar nuestras energías en las seleccionadas, y el tiempo promedio debía mejorar. Eso resultó ser así, como pudimos comprobar años después, en especial respecto a las investigaciones de abusos de posición dominante (con un descenso del 50 por ciento de su duración promedio entre el año 2012 y el 2017) y de fusiones (18 o 66 días promedio en fase 1 - según sea sin medidas o con medidas- o 97 en fase 2 , en contraste con una demora previa de meses ante una consulta ante el TDLC). ${ }^{63}$

La frase que sonaba en nuestras cabezas era menos es más, algo que sabíamos era difícil de explicar, y que podía ser malinterpretado, porque su entendimiento no es intuitivo y en nuestra cultura no se aprecia el foco y el precio que hay que pagar por ese foco.

Otro beneficio de elegir es que aumenta la tasa de investigaciones que se traducen en algún producto o acción concreta; esto es, requerimiento, consulta, acuerdo extrajudicial o cambio de conducta. Aquí no

${ }^{62}$ Ver Robert Jackson, “The Federal Prosecutor”, Journal of American Judicature Society 24 (1940): 19. Disponible en https://www.roberthjackson.org/wp-content/uploads/2015/01/The_Federal_Prosecutor.pdf. Ahí sostiene: "Law enforcement is not automatic. It isn't blind. One of the greatest difficulties of the position of prosecutor is that he must pick his cases, because no prosecutor can even investigate all of the cases in which he receives complaints. If the department of justice were to make even a pretence of reaching very probable violation of federal law, ten times its present staff would be inadequate. (...) What every prosecutor is practically required to do is to select the cases for prosecution and to select those in which the offense is the most flagrant, the public harm the greatest, and the proof the most certain". Las cursivas son nuestras.

${ }^{63}$ Sobre los plazos en las investigaciones sobre operaciones de concentración, ver Irarrázabal y Cerda, "Establecimiento de un...". 
hay azar. Es simplemente el resultado de haberlas seleccionado bien desde un principio. Así, uno puede elegir menos investigaciones y terminar con un número parecido e incluso mayor de acciones concretas de reprochabilidad. Así pudimos comprobar que era eficiente disminuir las investigaciones, e incluso pudimos medir el grado de eficiencia según la relación entre número de investigaciones y número de acciones concretas (distintas al simple cierre). Con ese índice de eficiencia, los resultados iban desde el 8 por ciento en el año 2010, al 41 por ciento el 2012 y 2013, hasta lograr el 61 por ciento el año 2014 y el 71 por ciento el año 2015. ${ }^{64}$

El control de la dirección de la FNE con los jefes de división se concentraba principalmente en dos momentos específicos: al principio y al final. Entremedio, se les daba a los jefes bastante libertad para conducir sus investigaciones, sin perjuicio de que se sostenían reuniones bilaterales con cada uno de ellos una vez por semana.

Al principio era, a mi juicio, el control más complejo, e implicaba una cuota de intuición, en decidir qué investigar y qué no, en el contexto de un ejercicio razonado de discrecionalidad. También había algo de "economía del hogar" y de oportunidad, en el sentido de aquilatar el costo de una investigación, lo que dependía del conocimiento que se tenía al interior de la FNE de ese mercado, de su sofisticación y de las posibles hipótesis contravencionales.

El segundo control era al final; esto es, cuando el equipo estaba convencido de que efectivamente había un reproche. Ahí, se producía una revisión afinada de los antecedentes concretos — la evidencia de la investigación- y se trabajaba en distintas versiones de un requerimiento o una consulta.

Había una autoexigencia de que los documentos finales fueran claros y al grano, y que no tuviesen grasa ni flecos innecesarios, ni menos errores de edición o tipeo. El estilo utilizado no era, de adrede, de gran pluma, sino que apegado a los hechos que luego íbamos a tener que probar.

El DL 211 contiene una norma que nos permitió ser selectivos. Se trata del artículo 41 sobre admisibilidades y que establece que ante denuncias de particulares la FNE dispone de un plazo de 60 días para pe-

${ }^{64}$ Ver Cuenta pública de la FNE de 2015 en http://www.fne.gob.cl/wp-content/uploads/2015/11/Cuenta_Publica_Propuesta-Final.pdf, 19. 
dir información y citar voluntariamente a declarar o pedir información, "para determinar si corresponde investigar o desestimar las denuncias que se formulen". ${ }^{65}$

A través de este mecanismo se podía, entonces, desestimar el inicio de una investigación por múltiples razones, lo que se tenía que traducir en una resolución por escrito que así lo declarara, a la cual se le adjuntaba un informe interno, que era público, sobre las actividades realizadas y las razones de la inadmisibilidad.

El mayor control que pudimos tener sobre las denuncias que se recibían se tradujo en la posibilidad de aumentar las investigaciones de oficio, y depender menos del flujo de solicitudes de afuera y desarrollar el músculo y el instinto al interior de la institución. Pudimos así aumentar el número de investigaciones de oficio por sobre las denuncias de particulares, y se llegó a que sobre el 50 por ciento de las investigaciones fueron de oficio. ${ }^{66}$

La selección se facilitaba debido a que la FNE no tiene monopolio alguno sobre las acciones ante el TDLC. Cualquier privado o autoridad puede accionar ante el TDLC, y no necesita que la FNE participe en ese proceso. De hecho, la mayoría de los casos de abusos de posición dominante ocurrían sin la participación de la FNE, y sólo en algunos de ellos el TDLC solicitaba un informe a la FNE. Ese aspecto de la institucionalidad chilena es sano, y le permite a la FNE focalizarse primordialmente en ciertas y determinadas conductas u operaciones (como carteles y fusiones), y en los casos en que está comprometido el interés general y no se perciba que existan otros actores que pudiesen asumir los costos de un juicio.

${ }^{65}$ La norma del artículo 41 del DL 211 está en armonía con el encabezado del artículo 39 y con los principios de eficiencia y eficacia de la Ley 18.575.

${ }^{66}$ Por ejemplo, la investigación del cartel del pollo empezó sin denuncia alguna. En algunos años, el porcentaje de investigaciones de oficio por sobre las que surgían de denuncias fue incluso muy superior al 50 por ciento. Ver Cuenta pública de la FNE de 2015 en http://www.fne.gob.cl/wp-content/uploads/2015/11/ Cuenta_Publica_Propuesta-Final.pdf, 16. La existencia de investigaciones de oficio es positiva, porque implica que la agencia está activa analizando los distintos mercados, y así disminuye un sesgo a focalizarse sólo en aquellos que presentan denuncias. Este sesgo a las denuncias, y la consiguiente reducción de investigaciones de oficio, ha sido una crítica constante que han debido enfrentar las agencias de países desarrollados. 
No sólo decidimos conscientemente limitar el número de investigaciones y aumentar el porcentaje de aquellas que se iniciaban de oficio, sino que además priorizamos áreas.

Hubo especial celo en los casos de carteles, porque teníamos la sensación de que ni los empresarios ni las autoridades les tomaban el peso a su gravedad como atentado a la economía de mercado.

La FNE instauró una política de cero tolerancia hacia los carteles, y lo demostró en los casos que investigó, requirió y ganó ante los tribunales. Cada caso de cartel es una historia aparte, pero lo importante fue fijar y explicitar una priorización en la política persecutoria contra los carteles, que se tradujo en la creación de una unidad de carteles y en el destino de recursos y horas hombres para esas investigaciones y juicios.

Esta política dio resultados, y se vieron victorias judiciales en casos emblemáticos, tales como en los de farmacias (iniciado bajo la administración anterior), de compresores de refrigeradores, de transporte interurbano (Curacaví, Cartagena, terminales, Caldera), de transporte intraurbano (Valdivia), de pollos, de asfalto, de navieras, de supermercados, de laboratorios (ampollas y sueros), de tissue y de doctores (Chillán y Quinta Región), por citar a los principales.

La otra prioridad fue fusiones, y ahí se hicieron muchos esfuerzos novedosos para poner el tema sobre la mesa, que ya fueron mencionados. Era muy incómoda la regulación raquítica con que teníamos que operar, y había muy buenos incentivos para que las empresas lisa y llanamente se concentraran sin consulta ni revisión alguna.

Además de la priorización de casos, hay otra faceta que requiere explicación y que se refiere a la selección de la herramienta adecuada a utilizar para un caso concreto.

La FNE dispone de un arsenal amplio de herramientas sancionatorias, en caso de una violación al derecho de competencia. ${ }^{67}$ La principal herramienta es el requerimiento o demanda de la FNE, con solicitudes de multas, pero también de modificaciones o términos de contratos e

${ }^{67}$ Un cambio administrativo a las metas de eficiencia institucional de la FNE, aprobado por la Dirección de Presupuestos, facilitó este enfoque selectivo en las herramientas a utilizar. Ese cambio consistió en modificar la meta de números de requerimientos por año por uno de "productos" por año, que incluía requerimientos, consultas y cambios de conductas. 
incluso disoluciones de entidades. ${ }^{68}$ Es una herramienta potente, pero cara. Implica destinar muchos recursos para prepararse para el litigio y ser efectivo. En los procesos legales pueden surgir múltiples variables difíciles de controlar o prever, por lo que se requiere estrategia. Los litigios también demoran, en especial si las controversias son álgidas y los contenedores poderosos, como normalmente ocurre en libre competencia.

Debido a las atribuciones que la ley le otorga a la FNE para investigar, al equipo de la fiscalía siempre se le exigió no verse sorprendido en el proceso mismo. Es decir, se trató de que durante la etapa de investigación se aquilataran bien los argumentos que las contrapartes podían hacer. Con eso, la FNE podía preparar bien sus argumentos e indagar en los hechos que sustentaban esos argumentos, y eventualmente podíamos llegar a convencernos de su bondad o mérito, si ése era el caso.

Eso había que hacerlo en la etapa de investigación, y si no se hacía ahí, entonces la pista se hacía cuesta arriba e incierta en el proceso mismo. La idea de arreglar la carga durante el viaje que implica todo litigio era algo descartado de plano.

Para mejorar la capacidad de detectar saltos en la investigación, establecimos un mecanismo interno de contrapeso: separamos las divisiones de investigación (carteles, abusos y fusiones) de la división de litigios. Así, la división de litigios comenzó a revisar toda la evidencia contenida en la investigación y a analizar si había algo pendiente y si se estaba de acuerdo o no con la tesis de la división de investigación pertinente.

Éste era un sano check and balance interno, adicional al contrapeso natural del TDLC, que costó al principio instaurarse por la enten-

${ }^{68}$ El artículo 26 del DL 211 dispone que: "En la sentencia definitiva, el Tribunal podrá adoptar las siguientes medidas: a) Modificar o poner término a los actos, contratos, convenios, sistemas o acuerdos que sean contrarios a las disposiciones de la presente ley; b) Ordenar la modificación o disolución de las sociedades, corporaciones y demás personas jurídicas de derecho privado que hubieren intervenido en los actos, contratos, convenios, sistemas o acuerdos a que se refiere la letra anterior; c) Aplicar multas a beneficio fiscal hasta por una suma equivalente al treinta por ciento de las ventas del infractor correspondientes a la línea de productos o servicios asociada a la infracción durante el período por el cual ésta se haya extendido o hasta el doble del beneficio económico reportado por la infracción. En el evento de que no sea posible determinar las ventas ni el beneficio económico obtenido por el infractor, el Tribunal podrá aplicar multas hasta por una suma equivalente a sesenta mil unidades tributarias anuales". 
dible tensión que se provoca al interior de los equipos de trabajo, pero que luego se apreció como un mecanismo de control de calidad que limita el sesgo de confirmación propio de las personas involucradas en la investigación. Además, aumentó la especialización, en tanto el equipo de la investigación no iba a participar en el litigio, y tenía entonces que orientar sus energías en las nuevas investigaciones que surgieran tan pronto el requerimiento fuese presentado.

Adicionalmente a los requerimientos, hay otras herramientas que pueden ser apropiadas para investigaciones determinadas, y que pueden implicar menores costos institucionales y conseguir resultados análogos.

Una de ellas son los acuerdos extrajudiciales, en los que la FNE tiene que detectar qué le parece reprochable, se lo comunica a las empresas y después hay negociaciones para ver cómo hacerse cargo de la conducta reprochable. El mecanismo contenido en el DL 211 ante el TDLC es sumamente expedito. ${ }^{69}$

Asimismo, a la FNE le puede resultar razonable y justo, en casos de menor importancia y efectos, aceptar cambios de conductas propuestos por las empresas, que no impliquen ni requieran de la participación del TDLC. Estos cambios de conducta pueden ser tanto o más relevantes que las multas que se pudiesen obtener, y sus efectos suelen ser inmediatos.

Por último, tanto la FNE como el TDLC tienen atribuciones para formular recomendaciones de cambios regulatorios o de dictación de normativa, con el objetivo de promocionar la libre competencia, y esta herramienta también puede ser útil y apropiada en determinados casos.

\section{TONO TÉCNICO}

Otro pilar del modelo de la FNE fue mantener un tono técnico, e incluso una cierta distancia con el debate encendido que surgía luego de las presentaciones en el TDLC de los casos importantes (en especial de carteles) o sobre las bondades o defectos de la economía de mercado.

${ }^{69}$ Ver artículo 39 letra ñ) del DL 211 e informes en derecho agregados a la causa rol n. ${ }^{\circ}$ 5418-2018 ante el Tribunal Constitucional, a propósito del acuerdo extrajudicial presentado el 27 de agosto de 2018 por la FNE y Tianqi Lithium Corporation. 
Esta actitud se ve reflejada con claridad en nuestras cuentas públicas:

Nos han ido dando mucho poder, (...) y precisamente por eso no podemos darnos el lujo de creer que las sabemos todas, que sólo nos tienen que dejar hablar o escribir porque no necesitamos ni escuchar ni leer. Podemos cometer errores. Podemos sufrir de miopía momentánea y omitir involuntariamente aspectos del mercado que debieran analizarse. $\mathrm{O}$ equivocarnos en predecir bien los cambios futuros que se van a producir en las distintas industrias. Pero bajo ningún pretexto podemos caer en la tentación, ahora más que nunca, del trabajo fácil, de la frivolidad, del populismo, del ingenio cortoplacista.

(...) Y que el carácter que la fiscalía ha ido construyendo desde hace décadas, de trabajo riguroso, de independencia y mirada de largo plazo, de sobriedad mediática y de alejamiento de la farándula y charlatanería, del partidismo y el populismo, es lo único que nos garantiza que vamos a poder enfrentar los nuevos desafíos que se nos presenten, de manera sensata, eficaz y eficiente (...). ${ }^{70}$

Se nos veía como tímidos, retraídos y poco energéticos; que no aprovechábamos nuestros minutos de gloria; que no se nos veía cómodos con los motes de sheriff o zar; que no teníamos complicidad con el gobierno de turno ni con los congresistas interesados en temas económicos; que desperdiciábamos la cobertura periodística que se nos ofrecía, en especial la televisiva y radial. Pero la estrategia fue mantener siempre la parquedad y la sobriedad, algo que considerábamos consustancial a un funcionario público, y que normalmente lo diferencia de un político. Considerábamos que eso nos permitía mantener el foco en los hechos crudos y la evidencia sólida de las investigaciones y de los litigios, y alejarnos de la frivolidad y tentación del adjetivo fácil.

70 "Cuenta pública de la Fiscalía Nacional Económica, del período 20152016", 2 y 13. Disponible en www.fne.gob.cl/wp-content/uploads/2018/04/ Discurso-Cuenta-Publica-040517.pdf. El discurso del fiscal Mario Ybar en el "Día de la competencia 2018" va en el mismo sentido: "Debemos, por un lado, alentar la confianza, la vigilancia — la indignación ante la transgresión, incluso-; pero también, por otro, evitar la instrumentalización y el populismo. Conservar ese equilibrio entre mantener vivo el compromiso social con la competencia, y no ceder con ella al populismo, estimo, será el principal desafío de la FNE para los tiempos que vienen". Las cursivas son nuestras. 
Había por cierto algo estético en esta decisión, de mirar el ejercicio de autoridad con una dignidad y prestancia, que no era compatible con actitudes livianas, declaraciones pomposas o ganancias de corto plazo. Ni con la fama. Pero sabíamos que lo que había en juego superaba la mera estética y se adentraba en la estrategia.

Por de pronto, no éramos ágiles con los medios de comunicación porque es muy difícil traducir la jerigonza legal y económica en palabras sencillas, sin perder precisión, como profundizaremos más adelante.

Además, los periodistas podían hacer buenas preguntas, pero era muy difícil dar buenas respuestas, o porque eso requería explicar muchos antecedentes previos (y los tiempos de la televisión y la radio son de minutos y de frases cortas), o no queríamos vernos en una posición de tener que adelantar argumentos que se podían venir en el litigio.

Nuestra estrategia con los medios de comunicación fue siempre la misma, y consistía en mantener un bajo perfil mediático, en especial en la persona del Fiscal Nacional Económico, pero un alto perfil en las labores de la FNE y su cobertura por la prensa especializada. Que en lo posible hablara la institución, más que la persona. ${ }^{71}$

Yo era renuente a dar entrevistas. Si las daba era por motivos puntuales, de preferencia no más de dos al año, y en medios escritos que permitían de mejor manera explicar las complejidades del derecho de competencia.

La idea detrás del bajo perfil era incentivar a los periodistas a que los casos hablaran por sí solos, y así se procuraba fortalecer una especialización en periodismo económico que cubriera las noticias de la FNE y el TDLC con autonomía, luego del análisis de los documentos que se hacían públicos, ya sea en el contexto de una investigación o en un litigio.

Nunca tuvimos inconvenientes en explicarles a los periodistas qué estábamos haciendo, respecto a casos públicos y a propósito de docu-

${ }^{71}$ Ver "Política general de comunicaciones de la FNE", julio 2018, disponible en http://www.fne.gob.cl/wp-content/uploads/2018/07/\%C3\%ADtica_comunicaciones.pdf. Fue muy útil también contar con la asesoría permanente de expertos comunicacionales externos, quienes semanalmente nos comentaban sobre las apariciones de la FNE y su contexto, y nos advertían sobre los nuevos desafíos que debían enfrentar las autoridades en la sociedad chilena. 
mentos específicos que ya estaban en la esfera pública. La traducción de eso a un lenguaje sencillo preferíamos no hacerla nosotros, sino que viniera de los propios periodistas, que estaban más capacitados que nosotros para así hacerlo.

Veíamos la utilidad de que hubiese una explicación sencilla, y fuimos con el tiempo puliendo las notas de prensa que salían desde la FNE para hacerlas más comprensibles, pero sin menoscabar su precisión técnica.

Tampoco quisimos corregir o contestar todas las cosas que se decían por la prensa (muchas de ellas incorrectas o descontextualizadas), sino sólo en casos excepcionales y cuando nosotros creíamos era el momento apropiado. La idea era no caer en la tentación de reaccionar a todas las instancias mediáticas que no provenían de la FNE, y así mantener el foco en las investigaciones y litigios.

Teníamos dos limitaciones importantes, una legal y la otra de buena administración. La legal era la confidencialidad con que teníamos que actuar y que requería ser diligente en que no se nos saliera nada que podría implicar una violación a esa confidencialidad. Donde mejor se puede hacer eso es ante el TDLC porque se presenta el escrito, pero con la información confidencial tachada.

La otra limitación era de buena administración de todo persecutor. No buscábamos el brillo efímero de la demanda, sino la contundencia de la sentencia. Como ya dijimos, la nuestra era una simple opinión, a través de un requerimiento. La verdadera decisión surge del fallo del TDLC y de su confirmación por parte de la CS, y entre un requerimiento y su fallo puede pasar mucha agua bajo el puente.

También había una preocupación porque el asunto reputacional no rebasase el costo de las consecuencias jurídicas del reproche anticompetitivo, con la convicción de que había que reconducir la discusión en el formato jurídico, que permite profundidad, textura y precisión.

Todo lo anterior no es fácil de conseguir en momentos cuando las discusiones públicas se daban bajo un tono vociferante y de escasa racionalidad, y cuando la popularidad de la economía de mercado estaba (o así lo sentíamos) en descenso o al menos en tela de juicio, en parte por la constatación de los abusos empresariales cometidos.

Era difícil dar a entender que los abusos de las empresas son inherentes a una economía de mercado, en la que prima la libertad y los actores privados tienen importantes cuotas de poder. El quid de la cues- 
tión no es que no existan, sino que exista una institucionalidad fuerte que pueda ir desbaratando carteles y abusos, controlando las operaciones de concentración y que tenga la suficiente musculatura para enfrentar eficazmente a un grupo económico o empresa poderosa ante los tribunales. La clave es poder contar con órganos estatales que puedan disuadir a las empresas de cometer actos contrarios a la libre competencia, lo que no se traduce en la ausencia de atropellos. No podía ser —ni queríamos- que el propio éxito de la FNE se tradujera en el desprestigio de la economía de mercado o del sector privado en su conjunto; es decir, que la conducta impropia e ilegal de unos pocos manchara y deslegitimara a todo un sistema social de organización que es probadamente eficaz y eficiente en la creación de riqueza. ${ }^{72}$

Creemos, sin embargo, que se logró un equilibrio sano entre, por un lado, la seriedad y confidencialidad que requerían nuestras investigaciones y el ejercicio de las atribuciones encomendadas, y, por el otro, la necesidad de toda autoridad de explicar lo que hace, que en el caso de la FNE involucra especialmente promocionar la libre competencia.

Teníamos, como parte de la estrategia, reuniones anuales con los editores de los principales medios de comunicación. Incluso algunos años lo hicimos con la televisión y la radio. Ahí les explicábamos qué hacíamos y comentábamos casos ya resueltos. Pero esencialmente aprovechábamos para explicarles el sistema institucional chileno y las complejidades del derecho de la competencia. Lo mismo hacíamos con los think tanks más relevantes de Chile, y ahí el foco eran los cambios legales que se requerían y, una vez aprobados, cómo se iban a ir implementando.

También organizamos talleres para periodistas del área económica, en los que explicábamos las últimas tendencias y los principales principios del derecho de la competencia. ${ }^{73}$

72 En el mismo sentido, ver el discurso del "Día de la competencia 2015", disponible en http://www.fne.gob.cl/wp-content/uploads/2015/11/discurso.pdf. Ahí se sostiene: "No se entierra la economía de mercado porque descubrimos que hay empresas e individuos que se aprovechan de ella. Es justo lo contrario: podría haber entierro, y un fracaso, si el Estado no se preocupa de defender a los mercados con todos los mecanismos legales" que tenga a la mano.

73 Ver, por ejemplo, http://www.fne.gob.cl/fne-realiza-taller-paraperiodistas-2017/. 


\section{EQUIPOS DE TRABAJO}

La FNE pudo consolidar a un equipo de alto rendimiento profesional en estos años, logrando atraer a los profesionales jóvenes más talentosos del mercado con inquietudes de servicio público. Sabíamos perfectamente que el factor clave de la FNE eran sus personas, y así lo manifestamos públicamente en varias oportunidades.

Los equipos funcionaban en forma afiatada y focalizada. Los jefes estaban debidamente empoderados. La gente podía trabajar en equipo y cada profesional sabía lo que tenía que hacer. Asimismo, la experiencia de haber trabajado en la FNE era considerada valiosa y formativa en el mercado laboral. ${ }^{74}$

Sabíamos perfectamente que el factor clave de la FNE eran sus personas, y así lo manifestamos públicamente en varias oportunidades:

La fiscalía es su gente, y es esa gente la que tiene que ir aplicando prudentemente y sin estridencia las reglas que nos gobiernan, en un trabajo que demanda no sólo inteligencia y conocimiento, sino que también carácter y disciplina. Todos y cada uno de sus funcionarios han sido seleccionados por su preparación académica, por su disposición hacia el trabajo grupal bien hecho, pero sobre todo por un carácter que les permite enfrentar desafíos y tensiones de una manera eficiente, eficaz y sana. Esa disposición y ese carácter permitieron, entre tanta jerigonza y teoría, preservar un cable a tierra, llamado sentido común. Esa disposición y ese carácter permitieron que las atribuciones y el poder entregados a la fiscalía no nublaran la vista de su equipo, y que se entendiera siempre que la modestia del trabajo bien hecho y la obsesión por los hechos han construido ladrillo a ladrillo este edificio de la libre competencia, cuyos cimientos se remontan al año $1959 .{ }^{75}$

${ }^{74} \mathrm{El}$ año 2017 hicimos una encuesta a los ex funcionarios de la FNE que trabajaron con nosotros en los últimos diez años, cuyos resultados se encuentran en http:// www.fne.gob.cl/wp-content/uploads/2017/12/Encuesta-a-ex-funcionarios.pdf. Anónimamente, el 91 por ciento de ellos evaluó en forma satisfactoria y muy satisfactoriamente su experiencia en la FNE, y el 95 por ciento dijo que recomendaría trabajar en la FNE. Pero algo aún más importante para la defensa y promoción de la libre competencia en nuestro país: el 51 por ciento dijo que siempre aplicaba conocimientos de libre competencia en su actual trabajo, y el 45 por ciento, que lo hacía ocasionalmente.

75 Ver la "Cuenta Pública de la Fiscalía Nacional Económica, del período 2015-2016”, en http://www.fne.gob.cl/wp-content/uploads/2018/04/Discurso-Cuenta-Publica-040517.pdf. 
Concebimos a la FNE con una estructura piramidal de base ancha. Eso implicaba que el promedio de edad de su equipo fuese bajo, asumiendo el desafío de una alta rotación. Se entendía que cada contratado iba a permanecer en la FNE entre dos años y medio y tres años. Sabíamos que era costoso el período inicial de aclimatación, y para acelerar ese proceso, que en algunos casos podía demorar un año, llevamos a cabo programas de inducción e instrucción.

¿Qué hicimos para atraer a los talentos jóvenes y competir eficazmente con los estudios de abogados, consultoras y otras reparticiones públicas?

Primero, cambiamos la estructura organizacional de la FNE, para hacerla más ágil y eficiente. La estructura anterior de la FNE descansaba en una división jurídica y otra económica. El diseño de la FNE al 2018, en cambio, se basaba en cinco divisiones: antimonopolios, carteles, fusiones, estudios y litigios, además de la administración y la dirección de la FNE.

Este diseño se fue dando de a poco en los años que lideramos la FNE, y resultó ser bastante eficiente. Se basa en la forma de organizarse que tienen los estudios de abogados y las consultoras. La idea es que una persona tiene capacidad para administrar efectivamente alrededor de 20 personas de alto rendimiento. Entonces la idea fue hacer grupos pequeños, con una función definida, y dar libertad a cada jefe para desarrollar su división.

Las claves eran, por supuesto, elegir a un excelente jefe o jefa para cada división y tener un control de calidad profundo, en especial al principio y al final de los casos, con un énfasis en aquellos que se traducían en requerimientos o consultas.

También quisimos tener un contrapeso efectivo para cada división de investigación; esto es, carteles, abusos y fusiones, en especial respecto de aquellas investigaciones que derivaban en litigios o procedimientos no contenciosos ante el TDLC (y eventualmente ante la CS). De ahí surgió la idea de crear una división de litigios que controlara cómo se había hecho la investigación y se focalizara en ganar los pleitos.

Quisimos, desde un principio, que los equipos profesionales de cada división combinaran abogados y economistas, optando por no tener dos compartimentos separados de acuerdo a la profesión de sus miembros, de forma que desde la investigación misma, y luego en el 
litigio, hubiese una eficaz simbiosis entre abogados y economistas. Esta fórmula fue además un gancho para atraer a los jóvenes profesionales de ambas profesiones, que consideraban estimulante trabajar en un ambiente interdisciplinario y con jefes altamente especializados, combinación que a los estudios de abogados les era difícil ofrecer de la misma manera. ${ }^{76}$

A agosto del 2018, la FNE contaba con 4 profesionales con grado de doctor, 4 como candidatos a doctor y 44 con grado de magíster, egresados de las mejores universidades de Chile y del mundo. ${ }^{77}$

Otro aspecto de la FNE atractivo para los jóvenes profesionales era la interacción con asesores externos - ya sean nacionales o extranjeros-, que enriquecía las discusiones internas y sofisticaba la mirada técnica. Había asesores especializados permanentes y otros transitorios, por ejemplo, para emitir un informe determinado que se iba a utilizar en un litigio. Siempre fuimos muy bien recibidos por los profesionales externos, quienes a mi juicio apreciaban trabajar con nosotros. ${ }^{78}$

${ }^{76}$ Además, esto se avenía muy bien con el derecho de competencia, que combina ambas disciplinas, en especial en un sistema como el chileno en el que dos ministros del TDLC son economistas.

${ }^{77}$ A esa fecha, la FNE contaba con profesionales egresados de las siguientes universidades: Georgetown University, Nueva York University, The London School of Economics and Political Science, Universidad Autónoma de Madrid, Universidad de Ámsterdam, Universidad de Barcelona, University College London, University of British Columbia-Vancouver, University of California-Berkeley, University of Cambridge, University of London-Birkbeck College, University of London-King's College, University of North Carolina at Chapel Hill, University of Oxford, University of Wisconsin-Madison y Yale University. Sin duda, el programa Becas Chile nos ayudaba, tanto para enviar a los profesionales de la FNE a perfeccionarse en el extranjero como para recibir a los que volvían de sus estudios.

${ }^{78}$ Durante el período 2010 a 2018, los siguientes profesionales prestaron servicios a la FNE, en temas de su experticia: Alan Frankel, Aldo González Tisinetti, Alexander Galetovic Potsch, Andrés Fuchs Nissim, Andrés Gómez-Lobo Echeñique, Antonio Bascuñán Rodríguez, Arturo Fermandois, Carlos Noton Norambuena, Carlos Pizarro Wilson, Carlos Portales Echeverría, Claudio Agostini González, Claudio Magliona Markovicth, Cristián Maturana Miquel, Eduardo Cordero Quinzacara, Eduardo Engel Goetz, Eleonora Ocello, Enrique Barros Bourie, Enrique Navarro, Enrique Vergara Vial, Felipe Bulnes Serrano, Fernando Coloma Ríos, Fernando Díaz Hurtado, Florian von Papp Wagner, Frederic Jenny, Ioannis Lianos, Jaime Arancibia Mattar, Jorge Bofill Genzsch, Jorge Correa Sutil, Jorge Grunberg Pilowsky, José Luis Lara Arroyo, José Luis Lima Reina, Juan Pablo Mañalich Raffo, Juan Pablo Montero, Julio Peña Torres, Leonardo Basso, Luis Barros Cabero, Luis Cordero Vega, Luis Morand Valdivieso, Marcelo Olivares Acuña, María So- 
También nos preocupamos de facilitar el estudio en el extranjero de los profesionales de la FNE, en especial a universidades anglosajonas, a través de orientación, contacto con tales instituciones y cartas de recomendación.

Inventamos un sistema de entrevistas a los candidatos, que también estaba fundado en contar con contrapesos efectivos. Queríamos a los mejores alumnos, que en general estuvieran dentro del 10 por ciento con mejores calificaciones de las facultades de derecho y economía líderes del país. Pero también queríamos diversidad y, sobre todo, integridad.

El sistema de contrapeso consistía en que los candidatos tenían que pasar dos filtros distintos. Por un lado, estaban las entrevistas que se hacían ante los profesionales de la división que los requería, y, por otro, las entrevistas con la dirección de la FNE. El proceso podía partir por uno u otro lado, pero tenía que ser siempre doble. Normalmente, las contrataciones partían por la división que necesitaba al profesional. Ellos se encargaban de buscar al candidato, entrevistarlo y seleccionarlo. De ahí tenía que pasar el filtro de la dirección de la FNE. Ese filtro consistía en dos entrevistas, una conmigo y otra con el subfiscal y con la jefa de relaciones institucionales. Las entrevistas eran separadas y no se producía ningún contacto entre los entrevistadores. Sólo al final del proceso nos reuníamos para comentar sobre el candidato.

En esas entrevistas el foco principal de la dirección de la FNE era analizar la integridad del candidato y su carácter para soportar, a pesar de su juventud, la presión y carga del poder. Como segundo criterio, se evaluaba su aporte a la diversidad de la FNE.

ledad Krause Muñoz, Mario Olivares González, Massimo Motta, Michael Carrier, Michael Jacobs, Miguel Chávez Pérez, Mona Chammas, Nicolás Figueroa González, Octavio Bofill Genzsch, Okeoghene Odudu, Ramiro Mendoza Zúñiga, Ramón Domínguez Águila, Raúl Núñez Ojeda, Ricardo Jungmann Davies, Ricardo Sanhueza Palma, Richard Whish, Roberto Plass Gerstmann, Rodolfo Fuenzalida Sanhueza, Siobhan Dennehy, Spencer Waller, Tom Ross, Tomás Rau Binder y Valentina Paredes Haz. Incluso la FNE publicó el año 2017 un libro que recoge algunos de los informes en derecho que solicitó y que presentó en determinadas causas. Ver $R e$ flexiones sobre el derecho de la libre competencia: Informes en derecho solicitados por la Fiscalía Nacional Económica (2010-2017). Disponible en http://www.fne. gob.cl/wp-content/uploads/2017/11/FNE-Libro.pdf. 
Otro cambio que hicimos se refirió al plan de procuradores. Ahí instauramos un programa atractivo para estudiantes de derecho, siguiendo los parámetros utilizados por los estudios de abogados, y lo principal era que sirviera como una plataforma para seleccionar a futuros profesionales de la FNE.

\section{INTERNACIONALIZACIÓN}

Ya hemos dicho varias veces que los centros de creación del derecho de la competencia residen en países como Estados Unidos y la Unión Europea. Hay otros que tienen actividades interesantes que vale la pena seguir, como Alemania, Australia, Canadá e Inglaterra. En Latinoamérica, Brasil ha sido especialmente fuerte en el tema de carteles, y México, en promoción de la libre competencia. Perú y Colombia han ido sofisticándose a grandes zancos, y Argentina estaba recién estrenando una nueva ley que prometía mostrar resultados.

Chile era visto como un país avanzado, con un esquema institucional interesante, pero el tamaño del mercado chileno no nos hacía un país especialmente gravitante, más si no teníamos un sistema de notificaciones de operaciones de concentración y el programa de delación compensada estaba recién empezando.

Sin embargo, la integración al mundo es importante en el derecho de la competencia, porque tanto las decisiones judiciales como las resoluciones y guías de afuera han tenido y tienen impacto en el derecho de la competencia nacional. Además, muchos de los desafíos que la autoridad nacional enfrenta ya han tenido alguna solución en el extranjero, como, por ejemplo, respecto a los temas de confidencialidad, a la interacción con otras autoridades regulatorias o la priorización al interior de la institución.

Así, es importante tener redes en las agencias extranjeras, que permitan llamar por teléfono ante alguna cuestión acuciante, poder hacer que un borrador de guía sea revisado por una agencia con experiencia en el tema y establecer lazos permanentes con los equipos de trabajo especializados en determinados mercados.

A través de reuniones en la Organización para la Cooperación y el Desarrollo Económicos (OCDE), International Competition Network (ICN), Conferencia de las Naciones Unidas sobre Comercio y Desa- 
rrollo (UNCTAD, por su sigla en inglés), foros anuales de la Fordham University y de la New York University, se fueron produciendo instancias de contactos con los jefes de las agencias y jefes de divisiones de los otros países. La pregunta era entonces cómo hacíamos para potenciar nuestras relaciones con agencias extranjeras y organismos internacionales y que al mismo tiempo fuera de interés para ellos ayudarnos, a pesar de nuestro tamaño.

La estrategia que utilizamos consistió en hacer esfuerzos para aumentar nuestra influencia en la región. Nos era fácil poder coordinarnos con las otras autoridades de Latinoamérica. No sólo debido a que el idioma facilitaba las relaciones, sino que además porque todos teníamos que navegar bajo el sistema del derecho continental y estructuras económicas con una tendencia hacia la monopolización por economías de escala.

En estos años, hicimos esfuerzos importantes de ayuda y asesoría a nuestros pares en Latinoamérica. Todos teníamos algo que aprender, por cierto. Pero Chile tenía una economía de mercado más adelantada que la mayoría de esos países, y eso hacía que a su vez el derecho de la competencia también mostraba un mayor avance en ciertas áreas.

Eso significó conversar con los jefes de servicios extranjeros de la región sobre desafíos institucionales y darles nuestra opinión, respetando la confidencialidad, pero también hacer que los equipos técnicos de los países participaran en sesiones de trabajo sobre temas de mutuo interés, participar en el Día de la Competencia de esos países, ayudándolos sobre casos concretos y facilitándoles materiales de estudio, entre otras actividades. ${ }^{79}$

Tan pronto las agencias de mayor experiencia se dieron cuenta de que Chile estaba ejerciendo un liderazgo regional, su actitud fue de mayor atención hacia nosotros. Se daban cuenta, y así se lo hacíamos saber, de que las enseñanzas y experiencias que podíamos recibir

79 Además, se crearon instancias multilaterales, en las que se compartían experiencias y conocimientos de mercados específicos. Ver, por ejemplo, "Declaración de Lima”, en la que Chile, Colombia y Perú acordaron crear un espacio de intercambio de experiencias entre las agencias de competencia en temas jurídicos o económicos y, además, fortalecer los mecanismos de cooperación y capacitación. Disponible en http://www.fne.gob.cl/wp-content/uploads/2013/09/dec_lima_2013. pdf. Algo similar se hizo posteriormente con México. 
de ellas las íbamos a diseminar en el resto de los países de Latinoamérica. ${ }^{80}$

Asimismo, hicimos un trabajo de acercamiento con los principales estudios de abogados internacionales. Les pedimos a los estudios de abogados nacionales que nos indicaran los estudios extranjeros con que ellos trabajaban, para que pudiéramos explicarles de primera mano nuestra normativa de delaciones compensadas y la nueva normativa de control de operaciones de concentración. ${ }^{81}$

\section{CONFIANZA}

El modelo de la FNE descansa en una piedra angular del edificio: la confianza. La independencia, el enfoque selectivo, el tono técnico, la excelencia de los profesionales y la internacionalización se anclan en la confianza en las instituciones y en el sistema, que depositan todos y cada uno de los actores involucrados. ${ }^{82}$

Sin confianza, no hay modelo que valga.

Quizás ésa es la clave esencial que explica nuestra sensación de consolidación y reputación institucional, en un contexto de un país desconfiado. ${ }^{83}$

${ }^{80}$ Quizás el indicador más objetivo de cómo mejoró la posición de la FNE en el ámbito internacional sea el ranking de agencias que cada año elabora Global Competition Review, calificando a las autoridades principales de todo el mundo. El sólo hecho de estar listado ahí era por cierto un honor. En esa lista, pasamos de tener dos estrellas en 2010 a 2,5 estrellas en 2011 y 3 estrellas en 2015. Otras muestras del éxito de integración de la FNE son el ingreso al bureau del Comité de Competencia de la OCDE, el ingreso de la División Anti Carteles al Grupo de Carteles de ICN, la presidencia del Comité de Competencia de APEC y el patrocinio de la primera reunión anual ISCI-Cresse en Latinoamérica para economistas.

${ }^{81}$ Aprovechamos las reuniones anuales de la American Bar Association, que ocurren una vez al año en Washington, DC, para visitar a los estudios de abogados internacionales y explicarles los cambios que venían. Eso nos ayudó a acelerar el acoplamiento a nivel internacional de nuestros programas de delación compensada y de notificaciones de operaciones de concentración.

${ }^{82}$ Ver "Cuenta pública 2017" del Fiscal Nacional Económico", en http://www. fne.gob.cl/wp-content/uploads/2018/04/Discurso_final.pdf.

${ }^{83}$ Ver "Panorama de la sociedad 2016, la situación de Chile, OECD", donde se sostiene: "Chile pertenece al grupo de países de la OCDE con bajos niveles de confianza: menos del 13 por ciento de los chilenos expresan confiar mucho en los demás (36 por ciento en la OCDE) (...); también, los jóvenes chilenos tienden a confiar menos en el gobierno que el resto de la población". Disponible en https:// www.oecd.org/chile/sag2016-chile.pdf. 
La confianza sirve para reducir la complejidad del futuro. La apertura total de lo que viene se limita por la vía de contar con que los sucesos del mundo o las acciones de otros se desarrollarán de acuerdo con ciertas generalizaciones que hemos construido a partir del presente y del pasado. ${ }^{84}$

Aunque arriesgada, la confianza es necesaria y urgente para posibilitar las decisiones y la acción en un mundo cada vez más abierto, cambiante y complejo.

La falta de confianza impide a las instituciones desplegarse y congela las actuaciones de los privados. La desconfianza en las instituciones es un costo infranqueable para el desarrollo económico, y quizás sea uno de los impedimentos claves que nos impide alcanzarlo.

La confianza aparece como el mecanismo más perfecto para alcanzar esa reducción de la incertidumbre, porque permite asegurar la libertad y la autonomía de todos los sujetos que entran en interacción, sin que se necesiten excesos de intervención o de costos de transacción.

La confianza se construye y se alimenta, y es un esfuerzo permanente el que subsista. Confiamos en las personas, pero también en las instituciones, y cada vez más necesitamos confiar en las instituciones en la medida en que la división del trabajo, la técnica y la globalización presentan altos niveles de complejidad e interdependencia.

Hay razones para confiar en una institución: la transparencia y el conocimiento de su estructura; el carácter técnico, el profesionalismo, la racionalidad en las actuaciones y la predictibilidad; la independencia en las decisiones; la seriedad en las actuaciones pasadas y la autoevaluación con miras a detectar errores y deficiencias y propender a su enmienda.

Todos esos factores hacen posible crear una expectativa y mantenerla en el tiempo, y permiten asimismo neutralizar posibles defraudaciones que naturalmente se puedan generar y que son el fruto natural de la necesaria flexibilidad con que el edificio institucional debe contar.

Esa confianza no significa, en modo alguno, captura del regulador $\mathrm{u}$ autoridad blandengue o indecisa. Significa más bien que las empresas deben suponer una autoridad alerta y firme, pero que va a actuar dentro de las vías legales, con independencia de cualquier factor que no arranque del caso concreto y con un tono discreto y ponderado, buscando resguardar de la mejor forma el interés público.

${ }^{84}$ Ver María Soledad Krause M. y Rodrigo González F., "La confianza en la construcción de la realidad social”, Revista de Filosofía 41, n. ${ }^{\circ} 1$ (2016): 33-53. 


\section{REFLEXIÓN FINAL}

Hasta ahora, la institucionalidad de libre competencia chilena ha sido exitosa, creemos, en lograr que exista un ambiente de confianza en el derecho de la competencia, en un país y en un mundo esencialmente desconfiado y litigioso.

Esa confianza se palpa en los investigados y demandados, y el mundo empresarial en general, que confía en que podrán desplegar sus argumentos en un ambiente racional y que los antecedentes serán efectivamente analizados de buena fe por quienes deben tomar las decisiones; en que se tomarán las medidas que franquea la ley para resguardar la confidencialidad de su información sensible; en que habrá un nivel sensato de predictibilidad respecto a las decisiones que podrían tomar las autoridades o al menos de las razones que explicarían ciertos ajustes; en que sus delaciones compensadas serán analizadas en su mérito y con estricta aplicación del principio de legalidad; en que en casos que así lo ameriten habrá espacio para llegar a acuerdos que satisfagan las pretensiones de las partes en conflicto y se resguarde el interés público; en que se buscará aplicar el verdadero sentido de la ley y no utilizar un caso concreto como pretexto para correr sus deslindes, y en un largo etcétera.

El gobierno, el Congreso y los políticos depositan confianza en la institucionalidad, y necesitan estar seguros de que, siguiendo los parámetros técnicos y las protecciones formales que exige la ley, la autoridad de libre competencia ha tenido, tiene y tendrá el coraje de enfrentarse a los poderosos, en forma eficiente y eficaz.

Los medios de comunicación también deben confiar en la institucionalidad respecto a que lo discutido está fielmente plasmado en los papeles del proceso o de la investigación; en que la jerga legal y la económica tienen una función de precisión y no de oscuridad, y en que las ritualidades del procedimiento facilitan un debate racional.

Es esta confianza la que le debiera permitir a la FNE sortear los desafíos que el derecho de la competencia le va a plantear con fuerza en un futuro cercano, en especial bajo el contexto de una economía digital.

Es la aplicación prudente, justa y proporcional de este modelo, ya asentado y pulido, inspirado en la independencia, enfoque selectivo, tono técnico, excelencia de sus profesionales e internacionalización, lo que debiera permitirle a la FNE seguir controlando eficiente y eficazmente los excesos del poder privado y profundizar la economía de mercado en Chile, a través de los cauces legales. 


\section{BIBLIOGRAFÍA}

Agüero, Francisco \& Santiago Montt. "Chile: The Competition Law System and the Country's Norms". En The Design of Competition Law Institutions: Global Norms, Local Choices, editado por E. Fox \& M. Trebilcock. Oxford: Oxford University Press, 2013.

Bernedo, Patricio. Historia de la libre competencia en Chile (1959-2010). Santiago: Fiscalía Nacional Económica, 2013.

Crane, Daniel. Antitrust. Nueva York: Wolters Kluwer Law, 2014.

Elhauge, Einer R. \& Damien Geradin. Global Antitrust Law and Economics. Foundation Press, 2018.

Ezrachi, Ariel. “Sponge”. Journal of Antitrust Enforcement 5 (2017).

Fiscal Nacional Económico. "Cuenta pública de la Fiscalía Nacional Económica 2015”. 2016. http://www.fne.gob.cl/wp-content/uploads/2015/11/Cuenta_ Publica_Propuesta-Final.pdf.

—. "Cuenta pública de la Fiscalía Nacional Económica, del período 20152016”. 2017. http://www.fne.gob.cl/wp-content/uploads/2018/04/DiscursoCuenta-Publica-040517.pdf.

—_. "Cuenta pública 2017". 2018. http://www.fne.gob.cl/wp-content/ uploads/2018/04/Discurso_final.pdf.

—_. "Discurso Día de la Competencia 2015". 2015. http://www.fne.gob.cl/wpcontent/uploads/2015/11/discurso.pdf.

—_. "Discurso Día de la Competencia 2016".

—. "Discurso Día de la Competencia 2017". 2017. http://www.fne.gob.cl/ wp-content/uploads/2017/11/Discurso-Fiscal-Felipe-Irarr por cientoC3 por cientoA1zabal-2017.pdf.

FNE. "Participaciones minoritarias y directores comunes entre empresas competidoras". 2013. http://www.fne.gob.cl/wp-content/uploads/2013/11/ Participaciones-minoritarias.pdf.

—. "Política general de comunicaciones de la FNE". 2018. http://www.fne. gob.cl/wp-content/uploads/2018/07/Pol por cientoC3 por cientoADtica_ comunicaciones.pdf.

- Reflexiones sobre el derecho de la libre competencia: Informes en derecho solicitados por la Fiscalía Nacional Económica (2010-2017). Santiago: Fiscalía Nacional Económica, 2017. http://www.fne.gob.cl/wp-content/ uploads/2017/11/FNE-Libro.pdf.

Gifford, Daniel J. \& Robert T. Kudrle. The Atlantic Divide in Antitrust: An Examination of US and EU Competition Policy. Londres y Chicago: University of Chicago Press, 2015.

González, Aldo \& Alejandro Micco. "Private versus Public Antitrust Enforcement: Evidence from Chile". Journal of Competition Law \& Economics 10 n. 3 (2014). 
Irarrázabal, Felipe \& Felipe Cerda. "Establecimiento de un sistema de control previo de operaciones de concentración en Chile: orígenes, implementación y desafíos". En Comentarios a la Ley de Defensa de la Competencia, dirigido por Demetrio A. Chamatropulos, Pablo Trevisán, Miguel del Pino. Buenos Aires: La Ley, 2018.

Jackson, Robert. "The Federal Prosecutor". Journal of American Judicature Society 24 (1940).

Jacobs, Michael. "Combatting Anticompetitive Interlockings: Section 8 of the Clayton Act as a Template for Chile and Similar Emerging Economies". 2013. http:/www.fne.gob.cl/wp-content/uploads/2013/11/Clayton-Act-Section-8. pdf.

"U.S. Antitrust Enforcement Involving Minority Shareholdings". 2013. http://www.fne.gob.cl/wp-content/uploads/2013/11/Minority-Shareholding-inthe-US.pdf.

Krause M., María Soledad \& Rodrigo González F. "La confianza en la construcción de la realidad social". Revista de Filosofia 41, n. ${ }^{\circ} 1$ (2016).

Landes, William. "The Fire of Truth: A Remembrance of Law and Econ at Chicago". Journal of Law and Economics 26 (1983).

Luhmann, Niklas. Confianza. Traducción de Darío Rodríguez Mancilla. Barcelona: Anthropos, 2005.

OCDE. "Competition and Market Studies in Latin America". 2015. www.oecd.org/ daf/competition/competencia-y-estudios-de-mercado-en-america-latina por ciento202015.pdf.

_. "Panorama de la Sociedad 2016, la situación de Chile, OECD". https:// www.oecd.org/chile/sag2016-chile.pdf.

Rivas, Virginia. "La reputación técnica y el emprendimiento de políticas como fuente de poderes: el caso de la Fiscalía Nacional Económica". Estudios Públicos 152 (2018).

Secretariado de la OCDE. "Evaluación del régimen de control de concentraciones en Chile". 2014. www.oecd.org/daf/competition/Chile por ciento20merger por ciento20control_ESP_nov14.pdf.

Valdés, Domingo. Libre competencia y monopolio. Santiago: Editorial Jurídica de Chile, 2006.

Vergara, Enrique. "Balance cuatrienio 2006-2010". 2010. http://www.fne.gob.cl/ wp-content/uploads/2010/12/inan_0005_2010.pdf.

Waller, Spencer Weber. "The Modern Antitrust Relevance of Oliver Wendell Holmes". Brooklyn Law Review 59 (1994). EP 